Aus der Klinik für Unfallchirurgie, Orthopädie und Plastische Chirurgie

(Prof. Dr. med. W. Lehmann)

der Medizinischen Fakultät der Universität Göttingen

\title{
Der Effekt von niedrigamplitudiger, hochfrequenter mechanischer Stimulation im Osteoporose-Rattenmodell
}

INAUGURAL - DISSERTATION

zur Erlangung des Doktorgrades

der Medizinischen Fakultät der

Georg-August-Universität zu Göttingen

vorgelegt von

Randa Galal

aus

Würzburg

Göttingen 2019 
Dekan:

Referent/in:

Ko-Referent/in:

Drittreferent/in:

Datum der mündlichen Prüfung:
Prof. Dr. med. W. Brück

Prof. Dr. med. S. Sehmisch

Prof. Dr. Dr. K. G. Wiese

28.07.2020 
Hiermit erkläre ich, die Dissertation mit dem Titel: „Der Effekt von niedrigamplitudiger, hochfrequenter mechanischer Stimulation im Osteoporose-Rattenmodell“ eigenständig angefertigt und keine anderen als die von mir angegebenen Quellen und Hilfsmittel verwendet zu haben.

Göttingen, den. 


\section{Inhaltsverzeichnis}

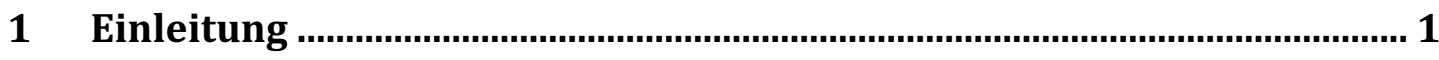

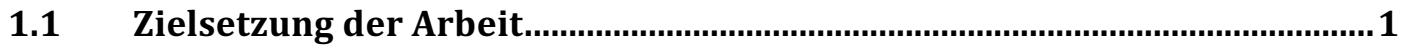

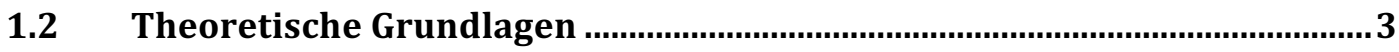

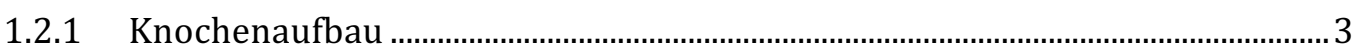

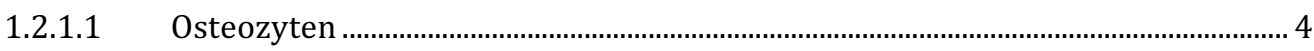

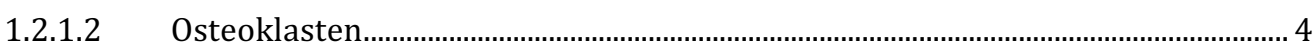

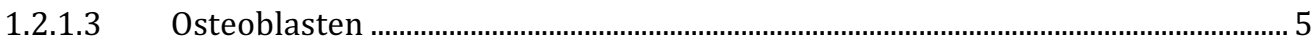

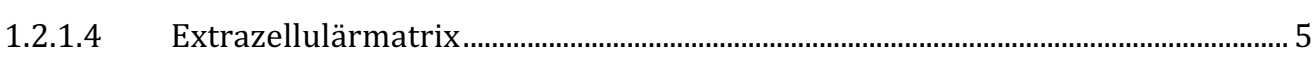

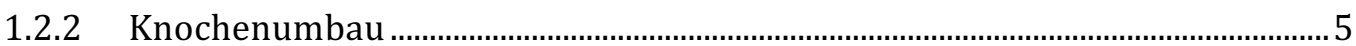

1.3 Osteoporose

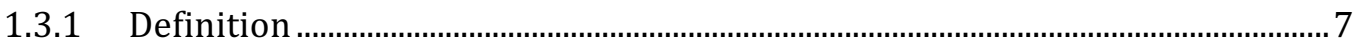

1.3.2 Epidemiologie ...........................................................................................................

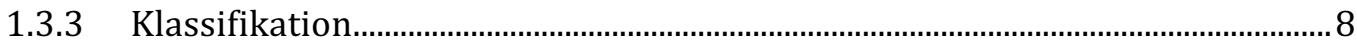

1.3.4 Pathogenese der postmenopausalen Osteoporose ……………………............ 10

1.3.5 Risikofaktoren ............................................................................................... 11

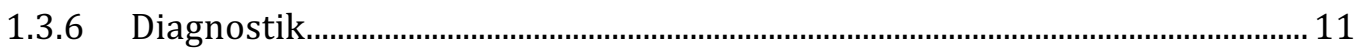

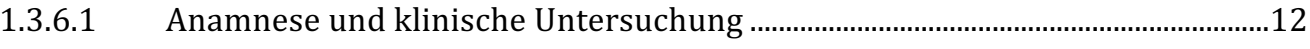

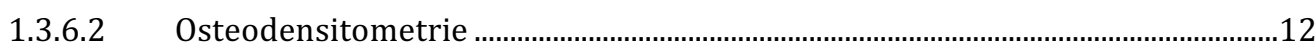

1.3.6.3 Konventionelles Röntgen .............................................................................................14

1.3.6.4 Basislaboruntersuchung.........................................................................................15

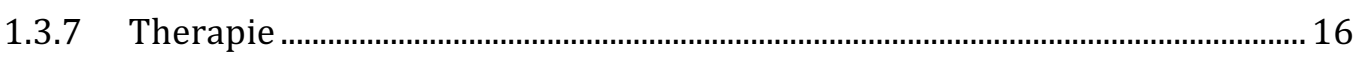

1.3.7.1 Präventionsmaßnahmen und Basistherapie ...........................................................16

1.3.7.2 Indikation zur medikamentösen Osteoporosetherapie ..........................................16

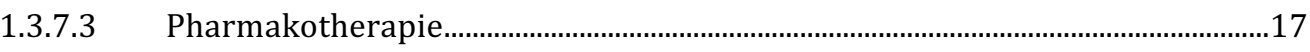

1.3.7.4 Postmenopausale Hormonersatztherapie (HRT) ……………………………….....19

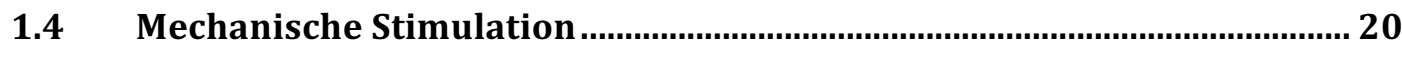

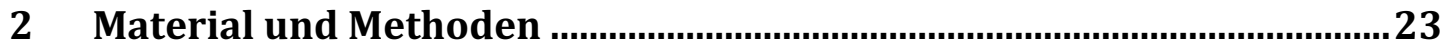

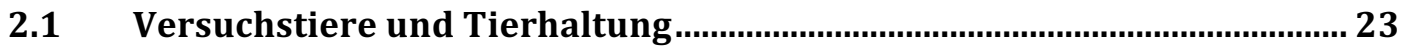

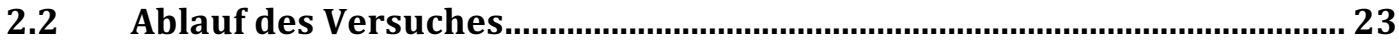

2.2.1 Ovarektomie der Versuchstiere .......................................................................... 24

2.2.2 Osteotomie der Versuchstiere ......................................................................... 25

2.2.3 Ganzkörpervibration der Versuchstiere ............................................................25

2.2.4 Futteraufnahme und Gewicht der Versuchstiere...............................................26

2.2.5 Präparation der Wirbelkörper ...............................................................................2 27 
2.2.6 Berechnung des Wirbelkörpervolumens........................................................27

$2.3 \quad$ Serumanalyse

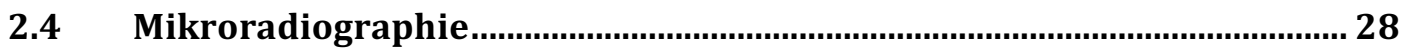

2.4.1 Histologische Präparation und Anfertigung der Mikroradiographien ......... 28

2.4.2 Digitalisierung der Mikroradiographien............................................................ 29

2.4.3 Auswertung der Mikroradiographien ................................................................. 30

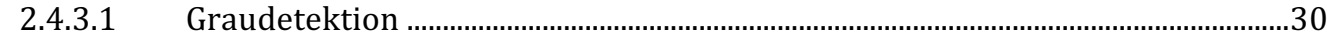

2.4.3.2 Ermittlung der Gesamtfläche des Wirbelkörpers.................................................31

2.4.3.3 Ermittlung der endostalen Gesamtfläche..................................................................31

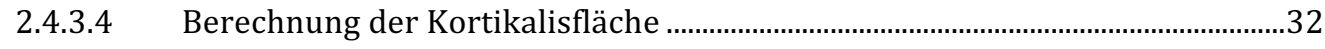

2.4.4 Messparameter der Mikroradiographie........................................................ 32

2.4.5 Eichung der Software ........................................................................................ 33

2.5 Biomechanischer Kompressionstest ............................................................. 33

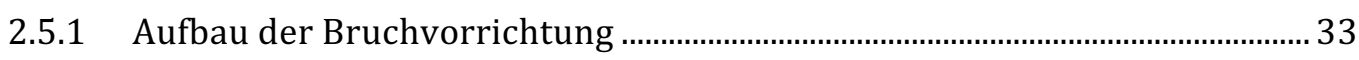

2.5.2 Durchführung des Kompressionstests ................................................................ 34

2.5.3 Messparameter des biomechanischen Kompressionstests .............................. 35

2.5.4 Kraft-Weg-Diagramm ........................................................................................ 35

2.5.5 Evaluation des Kompressionstests...................................................................... 36

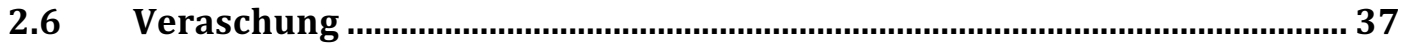

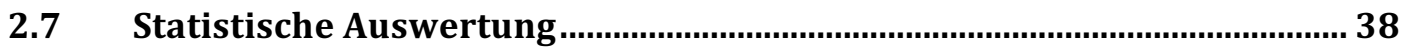

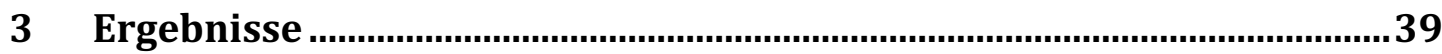

3.1 Ergebnisse der Messung der Tiergewichte und der Uterusgewichte ..... 39

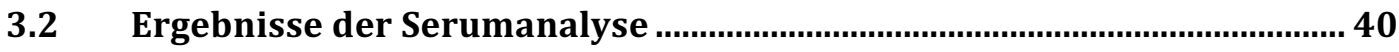

3.3 Ergebnisse der Mikroradiographie .......................................................... 41

3.3.1 Kortikale Knochenflächendichte ........................................................................ 41

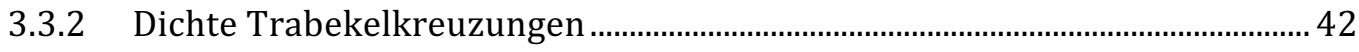

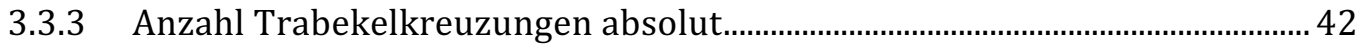

3.3.4 Trabekuläre Knochenfläche ............................................................................. 43

3.3.5 Mittlere Trabekeldicke ................................................................................................. 43

3.3.6 Zusammenfassung der Ergebnisse der Mikroradiographie ............................. 44

3.4 Ergebnisse des biomechanischen Kompressionstests.............................. 45

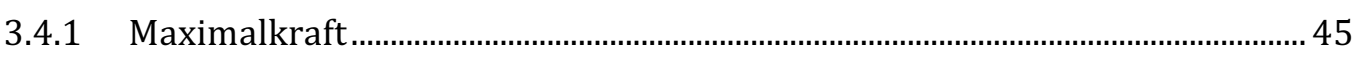

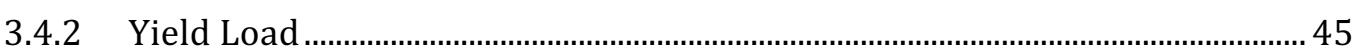

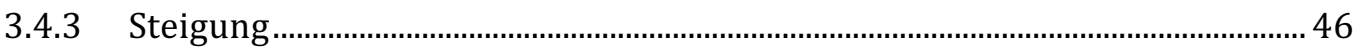

3.4.4 Zusammenfassung der Ergebnisse des biomechanischen

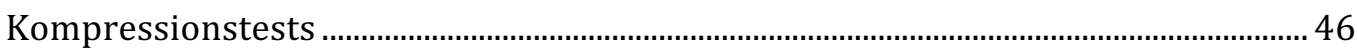

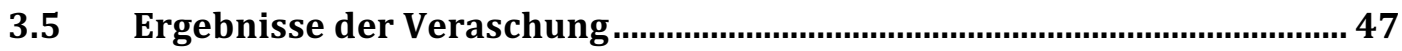




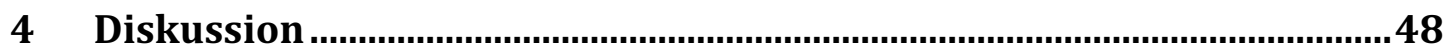

4.1 Die ovarektomierte Ratte als Tiermodell der Osteoporose ..................... 48

4.2 Analyse der Ergebnisse der Mikroradiographie ........................................ 49

4.3 Analyse der Ergebnisse des biomechanischen Kompressionstests ........ 51

4.4 Analyse der Ergebnisse der Veraschung ..................................................... 53

4.5 Deutung und kritische Betrachtung der Versuche......................................... 55

5 Zusammenfassung

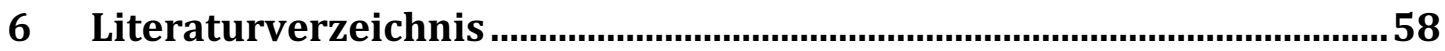

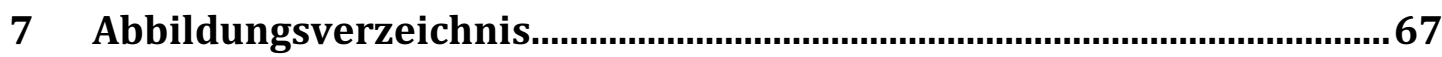

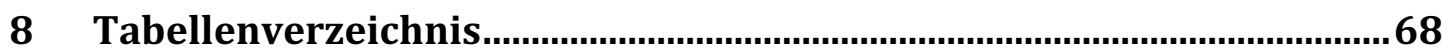




\section{Abkürzungsverzeichnis}

\begin{tabular}{|c|c|}
\hline ANOVA & analysis of variance \\
\hline ASBMR & American Society for Bone and Mineral Research \\
\hline BMD & bone mineral density \\
\hline BMI & body mass index \\
\hline BP & bone phosphatase \\
\hline BSG & Blutsenkungsgeschwindigkeit \\
\hline BUA & broadband ultrasound and attenuation \\
\hline $\mathrm{CO} 2$ & carbon dioxide \\
\hline COPD & chronic obstructive pulmonary disease \\
\hline DPD & Desoxypyrinidolin \\
\hline DVO & Dachverband Osteologie \\
\hline DXA & Duale X-Ray-Absorptiometrie \\
\hline ER & estrogen receptor \\
\hline $\mathrm{FSH}$ & Follikel-stimulierendes Hormon \\
\hline yGT & Gamma-Glutamyltransferase \\
\hline HRT & hormone replacement therapy \\
\hline $\mathrm{Hz}$ & Hertz \\
\hline IGF1 & insulin-like growth factor 1 \\
\hline $\mathrm{K}$ & Kelvin \\
\hline KG & Körpergewicht \\
\hline KHK & Koronare Herzkrankheit \\
\hline $\mathrm{kV}$ & Kilovolt \\
\hline LWK & Lendenwirbelkörper \\
\hline LWS & Lendenwirbelsäule \\
\hline $\mathrm{MHz}$ & MegaHertz \\
\hline MW & Mittelwert \\
\hline $\mathrm{N}$ & Newton \\
\hline $\mathrm{NaCl}$ & Natriumchlorid \\
\hline $\mathrm{OC}$ & Osteocalcin \\
\hline ovx & ovarektomiert \\
\hline $\mathrm{PICP}$ & Propeptid des Typ-I-Prokollagen \\
\hline PYD & Pyridinolin \\
\hline QCT & quantitative Computertomographie \\
\hline QUS & quantitative Ultrasound \\
\hline
\end{tabular}




$\begin{array}{ll}\text { SERM } & \text { selective estrogen receptor modulator } \\ \text { SOS } & \text { speed of sound } \\ \text { T3 } & \text { Trijodthyronin } \\ \text { T4 } & \text { Thyroxin } \\ \text { TSH } & \text { Thyreoidea-stimulierendes Hormon } \\ \text { Vib. } & \text { Vibration } \\ \text { WBV } & \text { whole body vibration } \\ \text { WBVV } & \text { whole body vibration vertical } \\ \text { WHO } & \text { World Health Organization } \\ \text { YL } & \text { Yield Load } \\ \text { ZTE } & \text { Zentrale Tierexperimentelle Einrichtungen }\end{array}$




\section{Einleitung}

\subsection{Zielsetzung der Arbeit}

Osteoporose ist eine systemische Skeletterkrankung, die charakterisiert ist durch eine niedrige Knochenmasse, den Verfall der Mikroarchitektur des Gewebes und eine daraus resultierende gesteigerte Knochenbrüchigkeit mit erhöhtem Frakturrisiko.

Aufgrund des weltweiten Vorkommens und der enormen sozialen und ökonomischen Folgen dieser Krankheit stellt die Erforschung bereits eingesetzter Therapeutika und die Entwicklung neuer Strategien zur Prävention und Behandlung von Osteoporose eine besondere Herausforderung dar (Lane 2006, Haussler et al. 2007).

Die derzeitige Osteoporosetherapie beruht neben generellen Maßnahmen zur Frakturprophylaxe sowie frühzeitiger Abklärung sekundärer Ursachen weitgehend auf Medikamenteneinnahme. Die unerwünschten Nebenwirkungen einer langjährigen pharmakologischen Therapie führten zu einer verstärkten Suche nach alternativen oder ergänzenden, nicht medikamentösen Therapieoptionen. Basierend auf der Tatsache, dass Knochen ein dynamisches Organ ist, welches befähigt ist, Masse und morphologische Struktur an äußere Einflüsse anzupassen, hat sich das Konzept der mechanischen Stimulation als möglicher Ansatz einer nicht invasiven Therapie entwickelt (Chan et al. 2013, Lau et al. 2010).

Wissenschaftliche Daten zeigen, dass eine mechanische Stimulation als eine Form der passiven körperlichen Aktivität einen anabolen Effekt auf Knochenmasse hat (Rubin et al. 2006). In einigen Studien wurden unterschiedliche Versuchstiere mit Osteoporose durch Ganzkörpervibration mechanisch gereizt und deren Knochen anschließend analysiert. Hierbei wurde die Applikationsform der Vibration in ihrer Dauer, Frequenz und Amplitude verschieden angewendet (Komrakova et al. 2017, Judex et al. 2007, Oxlund et al. 2003). 
Es ist noch nicht abschließend geklärt, welche Applikation des Reizes zu bestmöglichen Ergebnissen führt.

In der vorliegenden Arbeit wurde die Auswirkung der Ganzkörpervibration in Form von niedrigamplitudiger, hochfrequenter mechanischer Stimulation auf den osteoporotischen Knochen im Tiermodell getestet.

Als Versuchsmodell diente die ovarektomierte Ratte, die ein standardisiertes tierexperimentelles Modell für postmenopausale Osteoporose darstellt (Thompson et al. 1995, Ishihara et al. 1999). Zur morphologischen und biomechanischen Untersuchung der Knochen wurden die Lendenwirbelkörper der Tiere präpariert. Die Lendenwirbelsäule stellt eine der häufigsten Manifestationsorte der Osteoporose dar. Zudem besitzen vertebrale Frakturen eine hohe klinische Relevanz, da sie mit einem erhöhten unabhängigen Risiko für osteoporotische Folgefrakturen korrelieren und ein Indikator für den weiteren Verlauf der Erkrankung sein können (Hadjiuargyrou et al. 1998).

Ziel dieser Arbeit war es, den Effekt niedrigamplitudiger, hochfrequenter mechanischer Stimulation auf den Lendenwirbelkörper der osteoporotischen und intakten Ratte zu beurteilen. 


\subsection{Theoretische Grundlagen}

\subsubsection{Knochenaufbau}

Knochen ist ein dynamisches Organ, das sich aus Knochengewebe, Knorpel und blutbildendem Gewebe im Markraum zusammensetzt. Hinzukommen als Versorgungsstrukturen, Gefäße und Nerven. Hauptbestandteil ist dabei das Knochengewebe, das ein Verband von verschiedenen Knochenzellen, Knochenmatrix, einer kalziumreichen Extrazellulärsubstanz und Mineralien ist. Mit einer Dichte von 2-3 g/ml ist Knochen neben dem Zahngewebe das schwerste Gewebe im menschlichen Körper. Die mechanische Aufgabe dieses Organs ist, Belastbarkeit und Elastizität - bei möglichst niedrigem Gesamtgewicht - zu garantieren. Dies wird durch das Vorhandensein einer makroskopischen Architektur des Knochengerüstes gewährleistet. Unmittelbar unter der Knochenhaut, dem Periost, liegt eine Schicht dichten Knochens, die so genannte Substantia compacta. Diese ummantelt die weniger dichte Substantia spongiosa, die aus schwammartigen, an die Belastungslinien (Trajektionslinien) angepassten Knochenbälkchen (Trabekel) aufgebaut ist. Je dichter die Knotenpunkte der sich kreuzenden Bälkchen ausgebildet sind, desto stabiler ist der Knochen (Bartl 2008). Die trajektorielle Bauweise ist Folge biomechanischer Einflüsse auf den Knochen. Das schon 1892 von dem Berliner Anatomen und Chirurgen Julius Wolff veröffentlichte Gesetz sagt vereinfacht aus, dass sich äußere Form und innere Struktur des Knochens ständig an die externe, mechanische Beanspruchung anpassen (Wolff 1892). Vor allem im axialen Skelett, wie zum Beispiel der Wirbelsäule, findet sich Substantia spongiosa mit ihrer differenzierten Architektur. Zusätzlich besitzt spongiöser Knochen in diesem Skelettanteil eine größere Oberfläche und gegensätzlich niedrigere Gesamtmasse als kortikaler Knochen. Durch die Zusammensetzung aus schweren und leichten Anteilen des Knochengewebes wird ein Kompromiss zwischen maximaler Festigkeit und minimalem Gewicht eingegangen. Alle Oberflächen des Knochens sind außen von Periost und innen von Endost ausgekleidet, welche dünne Schichten aus knochenbildenden Zellen und Bindegewebe sind. Knochen ist ein Gewebe, das einem ständigen Umbau und der Anpassung an wechselnde Bedürfnisse ausgesetzt ist. Hierfür bedient sich der Knochen eines spezialisierten Zellsystems, das aus 
Osteozyten, Osteoblasten und Osteoklasten und Vorläuferzellen besteht (Bartl 2008, Junqueira und Carneiro 2005, Lippert 2003, Lüllmann-Rauch 2006).

\subsubsection{Osteozyten}

Osteozyten sind ehemalige Osteoblasten, die vollständig von mineralisierter Knochenmatrix umschlossen sind. Sie liegen in Höhlen (Lakunen) und sind mit ihren Fortsätzen, die sich durch verzweigte Kanäle (Canaliculi) erstrecken, untereinander verbunden. Die Lakunen sind zusätzlich mit interstitieller Flüssigkeit und Kollagenfibrillen ausgefüllt. Über Diffusion und Gap Junctions kann das gesamte Zellsystem miteinander in Verbindung treten (Lüllmann-Rauch 2006). Die Funktion der Osteozyten ist noch wenig erforscht und nicht ganz geklärt. Man vermutet, dass sie eine wichtige Rolle im Prozess des Knochenumbaus spielen. Einige Publikationen zeigen, dass Osteozyten die mechanisch sensitivsten Zellen im Knochengewebe sind (Turner et al. 2009, Vezeridis et al. 2006, Burger und Klein-Nulend 1999). Sie registrieren mechanische Reize auf den Knochen und initiieren die Signaltransduktion zu den umliegenden Osteoblasten und Osteoklasten. Diese Zellen können, im Gegensatz zu Osteozyten, Synthese leisten und so den Knochen an die externe Situation adaptieren. Hierbei scheint ein wichtiger Botenstoff neben Prostaglandine, TGF-ß1 und Stickstoffmonoxid (Lau et al. 2010) das, von Osteozyten produzierte Protein, Sklerostin zu sein. Sklerostin inhibiert den Aufbau von Knochensubstanz durch Osteoblasten. Mechanische Beanspruchung des Knochens bewirkt eine proportionale Hemmung der Sekretion, so dass Osteoblasten ihrer Funktion nachgehen können (Turner et al. 2009). Eine weitere Aufgabe der Osteozyten ist mutmaßlich die Knochenerhaltung, denn dort, wo sie absterben, wird die umliegende Knochenmatrix von Osteoklasten resorbiert (Junqueira und Carneiro 2005).

\subsubsection{Osteoklasten}

Osteoklasten sind große, stark verzweigte mehrkernige Riesenzellen, die Knochengrundsubstanz abbauen. Sie entstehen durch Fusion von aus dem Blut eingewanderten mononukleären Monozyten. Aktive Osteoklasten liegen der mineralisierten Knochenmatrix direkt an und resorbieren Knochen- 
gewebe. Dabei entstehen Einbuchtungen im Knochengewebe, so genannte Howship-Lakunen.

Die Rekrutierung, Differenzierung und Aktivierung der Osteoklasten werden durch verschiedene Hormone (Östrogen, Parathormon, Leptin, Schilddrüsenhormone) und Wachstumsfaktoren gesteuert. Wobei Östrogen vor allem die Rekrutierung der Osteoklasten unterdrückt (Bartl 2008).

\subsubsection{Osteoblasten}

Osteoblasten leiten sich von mesenchymalen Stammzellen ab, die zunächst, unter dem Einfluss von Hormonen und Wachstumsfaktoren, zu Vorläuferzellen, den Osteoprogenitor-Zellen, werden. Osteoblasten synthetisieren und sezernieren den organischen Teil der Knochengrundsubstanz, vor allem Kollagen, Proteoglykane und Glykoproteine. Sie liegen als einschichtiges Epithel auf der Oberfläche der Knochenbälkchen und geben ihre Syntheseprodukte in Richtung der Knochengrundsubstanz ab. Die neu gebildete, noch nicht verkalkte Knochengrundsubstanz wird als Osteoid bezeichnet. Dieses oppositionelle Knochenwachstum wird durch nachfolgende Mineralisation abgeschlossen (Junqueira und Carneiro 2005, Lippert 2003).

\subsubsection{Extrazellulärmatrix}

Die Knochenmatrix besteht zur Hälfte aus anorganischem Material, wobei Kalzium und Phosphat in Form von Hydroxyapatitkristallen den Hauptbestandteil ausmachen. Der organische Anteil der Matrix beinhaltet zu 95\% Kollagen Typ I, neben Proteoglykanen und Glykoproteinen. Die Kristalle lagern sich aufgrund ihrer Affinität zu Kollagenmolekülen den Kollagenfasern an. Diese Zusammensetzung aus zugfesten Kollagenfibrillen und druckfesten Mineralkristallen verleiht dem Knochen seine Härte und Widerstandsfähigkeit (Junqueira und Carneiro 2005, Lüllmann-Rauch 2006).

\subsubsection{Knochenumbau}

Erwachsener Knochen ist einem lebenslangen Umbauprozess (remodeling) ausgesetzt. Die unterschiedlichen Knochenarten unterliegen einem verschieden schnellen Umbau. Der kortikale Knochen, der 80\% der gesamten Masse ausmacht, wird aufgrund seines niedrigen Oberflächen- 
Nolumenverhältnis und seiner hohen Dichte sehr langsam umgebaut. Der spongiöse Knochen hingegen besitzt eine viel größere Angriffsfläche und wird sehr schnell umgebaut. Die jährliche Erneuerung der Spongiosa beträgt $25 \%$, die der Kortikalis 2,5\%. Das Verhältnis von 10:1 zeigt, dass sich ein Knochenverlust zuerst an der Spongiosa manifestiert, an Knochen mit großer Oberfläche (Bartl 2008).

Zweck des Remodelings ist die funktionelle Anpassung, Reparatur kleiner Perforationsbrüche der Knochenbälkchen (Mikrofrakturen) und die Mobilisation von Kalzium im Rahmen der Kalziumhomöostase. Sowohl lokale als auch systemische Faktoren beeinflussen den Knochenumbau, um den Knochen an den Muskelzug und äußeren Belastungen anzupassen. Zur Herstellung einer ausgeglichenen Bilanz im Knochenabbau und -aufbau steuern Zytokine und andere Mediatoren Osteoklasten und Osteoblasten. Die in diesem Zusammenhang zu erwähnenden Hormone sind Parathormon, Kalzitonin, Kortison, Insulin, Schilddrüsenhormone, sowie Wachstums- und Sexualhormone (Bartl 2008).

Die Knochenmasse im menschlichen Organismus resultiert dementsprechend aus dem Verhältnis von Knochenaufbau und -abbau. Bis zum 25-30. Lebensjahr nimmt die Knochenmasse auf physiologische Weise zu, bis sie abhängig vom Geschlecht, genetischem Potential, Hormonen und Umwelteinflüssen (Bewegung, Ernährung) einen Maximalwert (peak bone mass) erreicht hat. Dieser Wert ist ein Prädiktor für das spätere Auftreten von Osteoporose (Classen et al. 2004). Für die menschliche Wirbelsäule ist die maximale Knochenmasse zwischen dem dreißigsten und vierzigsten Lebensjahr erreicht (Rodin et al. 1990). Nach Erreichen der Plateauphase, wird die Bilanz der Knochenmasse negativ. Der jährliche Knochenverlust beträgt $1 \%$, wobei Wirbelkörper und proximales Femur, aufgrund des hohen Anteils an spongiösem Knochen, mehr betroffen sind als die übrigen Skelettareale. Bei Frauen, die sich nach der Menopause befinden, beschleunigt sich der Prozess des Knochenverlusts, infolge Östrogenmangels (Siris et al. 2002). 


\subsection{Osteoporose}

\subsubsection{Definition}

Die Definition der Osteoporose ist von Wissenschaftlern in der Vergangenheit immer wieder verändert worden. Die von den meisten Experten aktuell akzeptierte Definition ist im April 1993 auf der „International Consensus Development Conference on Osteoporosis" festgelegt worden und lautet:

„Die Osteoporose ist eine systemische Skeletterkrankung, die durch eine niedrige Knochenmasse und eine mikroarchitektonische Verschlechterung des Knochengewebes charakterisiert ist, mit einem konsekutiven Anstieg der Knochenfragilität und der Neigung zu Frakturen."

Die klinische Bedeutung der Osteoporose liegt im Auftreten von Knochenbrüchen und deren Folgen. Von einer manifesten Osteoporose spricht man, wenn bereits ein oder mehrere Knochenbrüche als Folge der Erkrankung aufgetreten sind. Eine weitere, diagnostisch anwendbare Definition wurde von der WHO 1994 erstellt. Sie besagt, dass eine Osteoporose dann vorliegt, wenn die Knochendichte 2,5 Standardabweichungen unter dem Mittelwert der Knochendichte gesunder Erwachsener zwischen dem zwanzigsten und vierzigsten Lebensjahr (TScore) fällt.

\subsubsection{Epidemiologie}

Osteoporose wurde von der WHO als eine der 10 wichtigsten Volkskrankheiten eingestuft und stellt mit geschätzten 200 Millionen Betroffenen, ein weltweites Gesundheitsproblem dar (Cooper 1999, Lane 2006). Laut der BoneEVA-Studie litten 2003 in Deutschland 7,8 Millionen Menschen im Alter von mindestens 50 Jahren an Osteoporose. Dies entspricht einer Prävalenz von 26\%. Die Prävalenz bei Frauen war mit 39\% deutlich höher ist als bei Männern mit 9,7\% und steigt bei beiden Geschlechtern im Alter stark an. Im Alter von 75 Jahren leiden zwei Drittel der Frauen an Osteoporose (59,2\%). Innerhalb dieser Studie hatten 4,3\% der Patienten eine osteoporotische Fraktur, wobei die häufigsten Lokalisationen dabei die Hüfte, das Handgelenk und die Wirbelkörper waren. Die enormen 
sozialen und ökonomischen Auswirkungen der Osteoporose werden in erster Linie durch die durch Osteoporose bedingten Frakturen verursacht. Im Jahr 2003 betrugen die Kosten pro Jahr 5.4 Milliarden Euro (Haussler et al. 2007).

Die Inzidenz der Osteoporose wird voraussichtlich unter Betrachtung der demographischen Bevölkerungsentwicklung und Veränderung der Lebensgewohnheiten weiter zunehmen (Hadji 2005).

\subsubsection{Klassifikation}

Die Einteilung der Osteoporose kann nach verschiedenen Aspekten erfolgen: Nach dem Schweregrad, der Ätiologie, dem Alter und Geschlecht, der anatomischen Ausdehnung und der Dynamik des Knochenumbaus.

Anhand des Schweregrades kann die Osteoporose in verschiedene Stadien gemäß der WHO-Klassifikation eingeteilt werden. Die Kriterien für die einzelnen Abstufungen richten sich nach der Knochendichte und dem Frakturnachweis (siehe Tab.1).

Tabelle 1: WHO-Klassifikation der Osteoporose (1994)

\begin{tabular}{l|l}
\hline Klinische Stadien & T-Score \\
\hline Normal & $\geq-1,0$ \\
Osteopenie & $-1,5$ bis $-2,5$ \\
Osteoporose (präklinisch) & $<-2,5$ \\
Osteoporose (manifest) & $<-2,5$ plus Fraktur \\
\hline
\end{tabular}

Nach ätiologischen Gesichtspunkten wird die Osteoporose in eine primäre Form ohne erkennbare Ursache und eine sekundäre Form mit erkennbarer Ursache eingeteilt, wobei die primäre Form weitaus häufiger ist. $\mathrm{Zu}$ den primären Osteoporosen zählen die idiopathische Osteoporose sowie die postmenopausale (Typ I) und senile (Typ II) Osteoporose. Die Ursachen der sekundären Osteoporose sind sehr vielfältig und in Tabelle 2 zusammengefasst. 
Tabelle 2: Ursachen einer sekundären Osteoporose

\begin{tabular}{|c|c|c|}
\hline $\begin{array}{l}\text { Gastroenterologische } \\
\text { Erkrankungen } \\
\text { Parenterale Ernährung } \\
\text { Malabsorption } \\
\text { Z.n. Gastrektomie } \\
\text { Schwere } \\
\text { Lebererkrankungen } \\
\text { Pankreatitis }\end{array}$ & $\begin{array}{l}\text { Hämatologische } \\
\text { Erkrankungen } \\
\text { Leukämie/Lymphome } \\
\text { Hämophilie } \\
\text { Sichelzellanämie } \\
\text { Thalassämie }\end{array}$ & $\begin{array}{l}\text { Medikamente } \\
\text { Glukokortikoide } \\
\text { Heparin } \\
\text { Antikonvulsiva } \\
\text { Chemotherapeutika } \\
\text { Thyroxin } \\
\text { Methotrexat }\end{array}$ \\
\hline $\begin{array}{l}\text { Endokrinologische } \\
\text { Erkrankungen } \\
\text { Cushing Syndrom } \\
\text { Alkoholismus } \\
\text { Hyperthyreodismus } \\
\text { Hypogonadismus } \\
\text { Akromegalie } \\
\text { Nebenniereninsuffizienz } \\
\text { Hyperparathyreodismus } \\
\text { Hyperprolaktinämie }\end{array}$ & $\begin{array}{l}\text { Genetische Erkrankungen } \\
\text { Turner-Syndrom } \\
\text { Marfan-Syndrom } \\
\text { Hämochromatose }\end{array}$ & $\begin{array}{l}\text { Verschiedenes } \\
\text { Alkoholismus } \\
\text { Immobilisation } \\
\text { COPD } \\
\text { Zystische Fibrose } \\
\text { Amyloidose }\end{array}$ \\
\hline $\begin{array}{l}\text { Rheumatologische } \\
\text { Erkrankungen } \\
\text { M. Bechterew } \\
\text { Rheumatoide Arthrits }\end{array}$ & $\begin{array}{l}\text { Mangelzustände } \\
\text { Kalzium } \\
\text { Magnesium } \\
\text { Vitamine D, K, C }\end{array}$ & \\
\hline
\end{tabular}

(Dietel et al. 2009)

Die häufigste Form der primären Osteoporose ist die postmenopausale Osteoporose (Typ I), die bei Frauen zwischen dem 51. und 75. Lebensjahr als Folge des Östrogenmangels auftritt. Diese manifestiert sich am trabekulären, spongiösen Knochen, der schneller und häufiger als der kortikale Knochen umgebaut wird. Die Wirbelkörper sind hier als Last tragende Knochen am stärksten bedroht.

Die postmenopausale Osteoporose geht stufenlos in die senile Form (Typ II) über, welche Frauen und Männer ab dem 70. Lebensjahr betrifft. Hier ist auch die Substantia corticalis betroffen mit Betonung der Röhrenknochen. Sie repräsentiert den Alterungsprozess und ist mit einer Zunahme der Osteoklastentätigkeit verbunden. Weiter Ursachen für einen gesteigerten Knochenumbau im Alter sind, Immobilität, defekter Vitamin-D-Metabolismus und sekundärer Hyperparathyreoidismus. Ungefähr $80 \%$ der osteoporotischen Frakturen sind der Typ II Osteoporose zuzuordnen. Eine klinische Relevanz hat die Differenzierung der beiden Osteoporoseformen jedoch nicht (Bartl 2008).

Weiterhin kann die Osteoporose, anhand der anatomischen Verteilung in eine generalisierte (systemische) Osteoporose und eine regionale (lokalisierte) 
Osteoporose eingeteilt werden. Die lokalisierte Form kann Folge von Inaktivität (z.B. Immobilität nach Frakturen oder Lähmung) oder bestimmten Krankheiten (Morbus Sudeck, Gorham-Syndrom u.a.) sein. Das generalisierte Auftreten, mit den Prädilektionsstellen Wirbelsäule und Oberschenkel, ist häufiger und kommt bei dem Typ I und Typ II Osteoporose vor.

Zusätzlich wird, entsprechend des Ausmaßes des Knochenumbaus, zwischen einer Osteoporose mit erhöhtem Knochenumsatz (high-turnover) und verminderten Knochenumsatz (low-turnover) unterschieden. Die Knochenmasse wird bei einer high-turnover-Osteoporose (z.B. Typ I) mit einem jährlichen Knochenmassenverlust von $>3 \%$ schneller abgebaut als bei der Low-turnover-Osteoporose, mit einem jährlichen Knochenmassenverlust von < 3\% (z.B. sekundäre Osteoporose aufgrund von Diabetes Mellitus Typ I) (Boskey et al. 2005).

\subsubsection{Pathogenese der postmenopausalen Osteoporose}

Vereinfacht ausgedrückt, entwickelt sich Osteoporose bei Entstehung eines Missverhältnisses zwischen Knochenaufbau und -abbau. Eine wesentliche Rolle in der Pathogenese postmenopausaler Osteoporose spielt der durch verminderte Ovarfunktion verursachte Östrogenmangel (Siris et al. 2002). Etwa $30 \%$ aller Frauen erkranken nach der Menopause an Osteoporose (Bartl 2008).

Die Knochenzellen Osteoblasten, Osteozyten und Osteoklasten exprimieren Östrogenrezeptoren (ER) vom Typ $\alpha$ und $\beta$. Östrogen beeinflusst vermutlich die Lebensspanne der Zellen, indem es die Apoptoserate dieser Zellen moduliert. Wichtige Botenstoffe hierbei sind Zytokine (Interleukin -1 und -6) und Wachstumsfaktoren (TGF $\beta$ ), welche durch Induktion der Apoptose von Osteoklasten die Gesamtbilanz des Knochens in Richtung Zunahme der Knochenmasse verschieben (Hughes et al. 1996, Pacifici 1998). Folglich bewirkt Östrogenmangel einen verstärkten Abbau des spongiösen Knochens im Bereich der Wirbelkörper und Oberschenkel mit entsprechender Frakturneigung.

Eine Studie mit 124 postmenopausalen Frauen konnte beweisen, dass eine frühe Menopause zwischen dem 40. und 45. Lebensjahr mit einer niedrigen Knochendichte korreliert. Eine lange Menstruationsphase und die damit 
verbundene hohe Östrogenproduktion scheint ein protektiver Faktor gegen die Entwicklung der postmenopausalen Osteoporose zu sein (Sioka et al. 2009).

\subsubsection{Risikofaktoren}

Eine Vielzahl von Risikofaktoren spielen bei Osteoporose, die pathogenetisch eine multifaktorielle Erkrankung ist, eine wichtige Rolle. Die Faktoren üben teilweise einen direkten Einfluss auf die Knochendichte aus, teilweise erhöhen sie jedoch auch unabhängig von der Knochendichte das Frakturrisiko. Nicht immer ist der zugrundeliegende Pathomechanismus bekannt. In Tabelle 3 sind die Schlüsselrisikofaktoren für osteoporosebedingte Frakturen zusammengefasst.

Tabelle 3: Risikofaktoren osteoporosebedingter Frakturen

\begin{tabular}{|lll|}
\hline Genetische Faktoren & Lebensstil & Krankheiten \\
Weibliches Geschlecht & Rauchen & Anorexia Nervosa \\
Familiäre Belastung & Alkoholkonsum & Multiples Myelom \\
Myelom & Chronischer & Hyperprolaktinämie \\
Kaukasische & Bewegungsmangel & Hyperthyreose \\
Abstammung & Übermäßiger Sport & \\
& Wiederholte Stürze & \\
Physische Faktoren & Ernährung & Medikamente \\
Niedriges Körpergewicht & Niedrige Kalziumaufnahme & Glukokortikoide \\
BMl<20kg/m² & Geringe Vitamin-D & Antiepileptika \\
Geringe Knochenmasse & Aufnahme & Heparinioide \\
& Hohe Phosphatzufuhr & Markumar \\
& Hohe Proteinzufuhr & Cyclosporin A \\
Östrogenmangel & & \\
Frühe Menopause & & \\
Späte Menarche & & \\
Verlängerte & & \\
prämenstruelle & & \\
Amenorrhö & &
\end{tabular}

(Bartl 2008, Dietel et al. 2009, International Consensus Development Conference 1993)

\subsubsection{Diagnostik}

Die klinische Abklärung der Osteoporose ist eine interdisziplinäre Aufgabe. Dabei sind eine frühzeitige Diagnosestellung und das Vermeiden der beeinflussbaren Risikofaktoren entscheidend für die erfolgreiche Therapie der Osteoporose und die Verminderung des osteoporotischen Frakturrisikos. Das diagnostische Ziel umfasst die Erstellung eines Risikoprofils, die Diagnosesicherung, die Bestimmung des Schweregrads und den Ausschluss 
einer sekundären Osteoporose. Die empfohlene Basisdiagnosik besteht aus Anamnese, klinischem Befund, einer DXA-Knochendichtemessung und einer bildgebenden Diagnostik zur Überprüfung prävalenter osteoporotischer Frakturen, sowie einem Basislabor (DVO 2009).

\subsubsection{Anamnese und klinische Untersuchung}

An erster Stelle steht eine ausführliche Anamnese mit Erhebung relevanter Risikofaktoren und Abklärung sekundärer Ursachen einer Osteoporose.

Die körperliche Untersuchung umfasst die Beurteilung der Körperhaltung, die Funktion des Bewegungsapparates und die Erfassung der Intensität und Lokalisation Frakturbedingter Schmerzen.

Durch Sinterung der Wirbelkörper kann ein massiver Größenverlust $(>4 \mathrm{~cm}$ ) der Patienten entstehen, während gleichzeitig der Hüft-Fußabstand konstant bleibt. Zwischen dem unteren Rippenbogen und dem Beckenkamm oder den Dornfortsätzen kann es zu einem schmerzhaften Kontakt, bedingt durch die Verkürzung des Rumpfes, kommen. Es zeigen sich charakteristische Hautfalten vom Rücken zu den Flanken, die als „Tannenbaumphänomen“ bekannt sind. Der typische Rundrücken, die Brustkyphose, ist ein weiteres Merkmal für den Einbruch der Brustwirbel. Diese charakteristischen Merkmale treten nicht bei allen Patienten auf und sind auch bei Vorliegen einer Osteoporose nicht beweisend für eine Fraktur (Bartl 2008).

\subsubsection{Osteodensitometrie}

Als Osteodensitometrie wird eine nicht invasive, indirekte Messung der Knochendichte (bone mineral density, BMD) bezeichnet. Sie ist die einzige Möglichkeit die Diagnose einer Osteoporose vor Auftreten einer Fraktur zu stellen. Weiterhin trägt die Knochendichtemessung zur quantitativen Abschätzung des individuellen Frakturrisikos bei. Ein vorhersehbarer Zusammenhang zwischen niedriger Knochendichte und erhöhtem Frakturrisiko konnte nachgewiesen werden (Watts 2004). Die unterschiedlichen zur Verfügung stehenden Densiometrieverfahren werden nachfolgend erläutert.

Das Grundprinzip der Knochendichtemessung beruht auf der Absorption von Röntgen- oder Photonenstrahlen durch Knochen, wobei diese Abschwächung weitgehend durch das Hydroxylapatit im Knochen bestimmt wird. Die 
abgeschwächte Röntgenenergie kann als Maß für die noch vorhandene Knochendichte ausgewertet werden. Die Schwächung wird je nach Methode in $\mathrm{g}$ Calciumhydroxylapatit $/ \mathrm{cm}^{2}$ oder in $\mathrm{mg}$ Calciumhydroxylapatit $/ \mathrm{ml}$ angegeben (Cummings et al. 2002, Hadji et al. 2001).

- Duale X-Ray Absorptiometrie

Das vom Dachverband Osteologie (DVO) und der WHO empfohlene Standardverfahren zur Knochendichtemessung ist die Duale X-RayAbsorptiometrie (DXA) an den Lendenwirbelkörpern 1 bis 4 und am proximalen Femur. Hierbei strahlen zwei Energiequellen unterschiedlicher Intensität durch das Gewebe. Anhand der Strahlenabsorption kann die BMD als Masse Knochenmineralstoffe pro Flächeneinheit $\left(\mathrm{g} / \mathrm{cm}^{2}\right)$ errechnet werden. Beeinträchtigungen der Auswertung können bestehen, wenn andere Kalkstrukturen (z. B. Osteophyten, Arteriosklerose) oder absorbierbare Substanzen (röntgendichte Kontrastmittel, Kalziumtabletten) in die Messung mit eingehen (Bartl 2008). Zur Diagnostik dieser Störgrößen ist die Anfertigung von Röntgenbildern indiziert. Es ist anzumerken, dass es sich hierbei um ein planares Verfahren handelt, indem der als Knochenmineraldichte bezeichnete Wert nicht der physikalischen Dichte entspricht, die als Masse pro Volumen $\left(\mathrm{g} / \mathrm{cm}^{3}\right)$ definiert ist.

Vorteile der DXA- Messung sind neben einer geringen Strahlenbelastung, der geringe Zeitaufwand und niedrige Kosten, weshalb sich das Verfahren auch für Verlaufskontrollen eignet (Watts 2004).

- Quantitative Computertomograpie

Weiterhin besteht die Möglichkeit der Anwendung der quantitativen Computertomographie (QCT), die als dreidimensionales Volumenmessverfahren die ermittelten Werte in Masse Hydroxylapatit pro Volumen angibt $\left(\mathrm{g} / \mathrm{cm}^{3}\right)$ (Hadji et al. 2001). Die Messung der echten physikalischen Dichte und die hohe Präzision der Messung ist ein Vorteil gegenüber der DXA. Ebenso ist die Unterscheidungsmöglichkeit von spongiösen und kompakten Knochen von Vorteil. Sie ist die beste Methode, um den für die Wirbelsäule typischen Verlust von trabekulärem Knochen früh zu erkennen. Aufgrund der schlechten Reproduzierbarkeit des Messortes und der hohen 
Strahlenbelastung ist dieses Verfahren für Kontrollmessungen jedoch weniger qualifiziert.

- Quantitativen Ultraschallmessung

Mit der quantitativen Ultraschallmessung (quantitative ultrasound, QUS) steht seit einigen Jahren eine röntgenstrahlfreie, kostengünstige und portable Messmethode zu Verfügung. Hierbei werden Ultraschallwellen in einem Frequenzbereich von 0,25- 1,25 MHz eingesetzt, die im Knochen und an der Knochenoberfläche gemessen werden und durch physikalische Eigenschaften des Knochens in ihrer Form, Intensität und Geschwindigkeit beeinflusst werden. Dabei werden nicht nur Informationen über die Knochendichte, sondern auch über die Knochenstruktur und Architektur gewonnen. Genutzt werden dafür die Parameter Ultraschall-Geschwindigkeit (speed of sound $=$ SOS $\mathrm{m} / \mathrm{s}$ ) und Breitbandultraschallabschwächung (broadband ultrasound and attenuation, BUA), dB/MHz (Glüer et al. 2006, Hadji et al. 2001). Da die Messung mit Schallsender und gegenüber positionierter Schallempfänger erfolgt, eignen sich gut zugängliche Knochen, wie Calcaneus, Radius und Phalangen, als Messorte. Aufgrund der einfachen Anwendung und der fehlenden Strahlenbelastung hat sich die QUS als Screening-Methode durchgesetzt, kann jedoch die DXA-Messung im Bereich der Wirbelsäule und des Femurs bisher nicht ablösen (Bartl 2008).

\subsubsection{Konventionelles Röntgen}

Konventionelle Röntgenaufnahmen der Wirbelsäule gehören zu den diagnostischen Maßnahmen der Osteoporose. Zur Frühdiagnostik sind sie jedoch nicht geeignet, da sich Knochendichteverluste erst ab einem Mineralsalzverlust von 30-40\% darstellen lassen. Das bildgebende Verfahren ist allerdings wesentlich zur Erfassung von bereits stattgefundenen stummen Frakturen und Grund- und Deckplatteneinbrüchen der Wirbelkörper. Empfohlen wird es bei akuten, neu aufgetreten, starken und/oder unverändert über Tage anhaltenden Rückenschmerzen und chronischen Rückenschmerzen, die bisher nicht abgeklärt worden sind (DVO 2009). Weiterhin sind Röntgenbilder der Wirbelsäule zum Ausschluss einer sekundären Osteoporose unentbehrlich. Sie zeigen charakteristische Veränderungen vor 
allem bei degenerativ-entzündlichen Gelenkerkrankungen, metabolischen Osteopathien und malignen Knochenläsionen (Bartl 2008).

\subsubsection{Basislaboruntersuchung}

Eine Basislaboruntersuchung wird zum Ausschluss der wichtigsten sekundären Osteoporosen und differentialdiagnostisch in Frage kommenden anderen Osteopathien (z. B. Osteomalazie) empfohlen. Folgendes laborchemisches Screening wird regelmäßig durchgeführt (DVO 2009):

Kleines Blutbild, BSG, Kalzium, Phosphat, alkalische Phosphatase, Y-GT, Kreatinin und Transaminasen. Nur bei entsprechender Indikation werden zusätzlich Schilddrüsenhormone (T3, T4, TSH), Geschlechtshormone (FSH, Östrogen, Testosteron) und Vitamin-D-Metabolite (Calcitriol, 25-HydroxyVitamin D) sowie Parathormon untersucht.

Aussagen über das Ausmaß des Knochenumbaus (high-turnover und lowturnover-Osteoporose) können mithilfe der Bestimmung von Knochenmarkern im Blut oder Urin gemacht werden. Dies kann zur Beurteilung des medikamentösen Therapieerfolgs nützlich sein. $\mathrm{Zu}$ den empfindlichsten Knochenformationsparametern, welche von den Osteoblasten produziert werden, gehören die alkalische Knochenphosphatase (BP), das carboxyterminale Propeptid des Typ-I-Prokollagen (PICP) und Osteocalcin (OC). Zeichen einer erhöhten Knochenresorption sind erhöhte Spiegel von Kollagenbausteinen und Kollagenquervernetzungsprodukten („Cross-links“). $\mathrm{Zu}$ diesen zählen Pyridinolin (PYD) und Desoxypyrinidolin (DPD), sowie carboxyterminales und aminoterminales Typ I Kollagen Telopeptid. Bei Messung dieser Marke, sind erhebliche Tagesschwankungen zu beachten (Bahlous et al. 2006, Eastell und Hannon 2008, Garnero 2008).

Eine Erhöhung biochemischer Marker hat sich als ein unabhängiger Risikofaktor für Frakturen gezeigt (Eastell und Hannon 2008). Dennoch hat sich die Bestimmung von Knochenmarkern im Blut oder Urin innerhalb der Routinediagnostik, aufgrund von mangelnder Standardisierung dieser Parameter unter klinischen Alltagsbedingungen und fehlender Evaluation im Zusammenhang mit anderen Risikofaktoren, bisher nicht durchgesetzt (Bartl 2008). 


\subsubsection{Therapie}

$\mathrm{Zu}$ den Therapieoptionen der Osteoporose gehören die allgemeinen Präventions- und Basismaßnahmen sowie die spezifische Pharmakotherapie. Allgemeine Ziele der Therapie sind die Reduktion der Frakturinzidenz, die Erhaltung der Funktionsfähigkeit des Skeletts und der Lebensqualität der Betroffenen.

Die folgenden Kapitel beziehen sich auf die vom Dachverband Osteologie veröffentlichte Empfehlung zur Prophylaxe, Diagnostik und Therapie der Osteoporose beim Erwachsenen (DVO 2009).

\subsubsection{Präventionsmaßnahmen und Basistherapie}

Bei allen Patienten mit einem erhöhten Risikoprofil werden unabhängig von der spezifischen Pharmakotherapie, Maßnahmen zur Prophylaxe von Frakturen empfohlen. Eine wichtige Voraussetzung hierfür ist die Aufklärung und Motivation der Betroffenen zur individuellen, eigenverantwortlichen Prävention durch einen knochenbewussten Lebensstil. Hierzu gehört die konsequente körperliche Aktivität, durch die Sicherheit beim Gehen und in der Koordination gewonnen wird. Dadurch wird nicht nur eine Immobilisation verhindert und eine Stimulation des Knochen- und Muskelaufbaus gestärkt, sondern auch das Sturzrisiko, das vor allem im Alter erhöht ist, gesenkt. Patienten, die in ihrer Motilität durch Angst vor Sturzereignissen oder Frakturen eingeschränkt sind, werden psychosoziale Betreuung und Selbsthilfegruppen angeboten. Weiterhin sollte auf eine ausgewogene Ernährung mit kalziumhaltigen Nahrungsmitteln geachtet werden, um den täglichen Kalziumbedarf von 1000 mg zu decken. Kann dies durch Ernährung nicht gewährleistet werden, ist eine Supplementierung empfohlen. Dies gilt auch für die Zufuhr von Vitamin D. Bei einer unzureichenden Sonnenlichtexposition sollten 400 bis 800 Einheiten Vitamin D3 gegeben werden (Gennari 2001). Zur Prävention gehört außerdem, bestehende Risikofaktoren zu erkennen und, wenn möglich, zu vermeiden.

\subsubsection{Indikation zur medikamentösen Osteoporosetherapie}

Eine spezifische medikamentöse Therapie wird unabhängig vom Geschlecht und Alter empfohlen, wenn aufgrund von vorhandenen epidemiologischen 
Daten das geschätzte 10-Jahresrisiko für Wirbelkörper- und proximale Femurfrakturen über $30 \%$ liegt und die T-Werte der DXA-Messung an einer dieser Lokalisationen vermindert sind.

Bei pathologischen einfachen Wirbelkörperfrakturen 2. oder 3. Grades nach Genant (Höhenminderung von 25-40\% bzw. > 40\%) oder mehrfachen Wirbelkörperfrakturen 1.-3. Grades und einem T-Wert von -2,0 wird ebenfalls eine Pharmakotherapie empfohlen. Die Reduktion des Frakturrisikos um 30$40 \%$ bei einem DXA-T-Wert unter -2 durch die Einnahme von Medikamenten ist erwiesen. Eine weitere Indikation hierfür, ist die tägliche Applikation von mehr als 7,5 mg Prednisolonäquivalent für mehr als drei Monate, bei gleichzeitigem T-Wert $\leq-1,5$.

Wenn keine Risikofaktoren oder stattgehabte Frakturen vorliegen, kann bei Unterschreiten folgender T-Werte (siehe Tabelle 4) in Abhängigkeit von Alter und Geschlecht ebenfalls eine medikamentöse Therapie durchgeführt werden.

Tabelle 4: Indikation zur Medikamentösen Therapie in Abhängigkeit vom T-Wert im Bezug zum Geschlecht und Alter

\begin{tabular}{c|c|c}
\hline \multicolumn{2}{c|}{ Lebensalter in Jahren } & \multicolumn{2}{c}{$\begin{array}{c}\text { T-Wert } \\
\text { (DXA LWS oder proximaler Femur) }\end{array}$} \\
\cline { 1 - 2 }+ & 0 & $-4,0$ \\
$50-60$ & $60-70$ & $-4,0$ \\
$60-65$ & $70-75$ & $-3,5$ \\
$65-70$ & $75-80$ & $-3,0$ \\
$70-75$ & $80-85$ & $-2,5$ \\
$>75$ & $>85$ & $-2,0$ \\
\hline \multicolumn{2}{c}{ DXA= Duale X-Ray-Absorptiometrie } \\
\hline
\end{tabular}

(DVO 2009)

\subsubsection{Pharmakotherapie}

Zur medikamentösen Therapie der Osteoporose stehen mehrere Substanzen zur Verfügung. Das Ziel der Pharmakotherapie ist die Senkung des Risikos von Wirbelkörperfrakturen und die effektive Vorbeugung peripherer Brüche. Laut der DVO-Leitlinie 2009 sind, in Bezug auf diese Ziele, die besten Therapieoptionen bei der postmenopausalen Frau Bisphosphonate, Östro- 
gene, Raloxifen, Strontiumranelat und Parathormon. Bei all diesen Präparaten wurde im vergleichbaren Umfang eine Verminderung von Wirbelkörperfrakturen nach 3 Jahren nachgewiesen. Die Dauer der Medikamentenapplikation sollte grundsätzlich mindestens 3-5 Jahre betragen und den Zeitraum abdecken, für den ein erhöhtes Frakturrisiko besteht. Ausschließlich bei Parathormon liegt die Grenze der Therapiedauer bei 25 Monaten.

Im Folgenden sind die genannten Therapeutika kurz aufgeführt:

- Bisphosphonate

Schon seit 30 Jahren spielen die Bisphosphonate eine wichtige Rolle in der Prävention und Behandlung verschiedener Osteoporoseformen und anderer Knochen- und Kalziumstoffwechselerkrankungen (McClung et al. 2001). Bisphosphonate werden, aufgrund ihrer hohen Bindungsaffinität zu Hydroxylapatit, der Knochenoberfläche angereichert und hemmen dort die osteoklastäre Knochenresorption, wodurch sie zu einer positiven Knochenbilanz führen. Sie sind somit potente antiresorptive Substanzen.

In mehreren Studien wurde für die Bisphosphonate Alendronat, Risedronat, Ibandronat und Zoledronat eine gute Effektivität für die Senkung des vertebralen Fraukturrisikos erwiesen. So konnten u. a. die BONE-Studie, die Ergebnisse des Hip Intervention Program und der VERT-Gruppe die Wirksamkeit von Bisphosphonate in der Osteoporosetherapie beweisen (Delmas et al. 2004, McClung et al. 2001, Harris et al. 1999, Reginster et al. 2000).

\section{- Raloxifen}

Raloxifen gehört zu der Gruppe der selektiven Östrogenrezeptormodulatoren (selective estrogen receptor modulators, SERM). Diese stellen östrogenartige, nicht steroide Substanzen dar, die ihre Wirkung in verschiedenen Geweben über Östrogenrezeptoren vermitteln (ERa und $E R \beta)$. Am Knochen führt Raloxifen als Östrogen-Agonist durch Hemmung der Osteoklasten zu einer Umkehrung des progedienten Knochenmasseverlusts. Am Brust- und Endometriumgewebe wirkt es dagegen als ÖstrogenAntagonist (Cranney et al. 2002). 
- Strontium-Ranelat

Strontium-Ranelat ist seit 2004 in einer Dosierung von $2 \mathrm{~g} / \mathrm{Tag}$ für die Therapie der postmenopausalen Osteoporose zugelassen. Es handelt sich dabei um eine knochenaffine Substanz aus der Gruppe der Erdalkalimetalle, die in ihrer chemischen Zusammensetzung eine Ähnlichkeit zu Kalzium besitzt. Dieses Medikament weist einen dualen Wirkmechanismus auf, wobei es sowohl einen anabolen als auch einen antiresorptiven Effekt am Knochen erzielt. Es steigert die Differenzierung der Präosteoblasten und stimuliert die Kollagensynthese reifer Osteoblasten, während es gleichzeitig die Knochenresorption durch Inaktivierung der Osteoklasten und deren Vorläuferzellen hemmt (Marie 2005).

\section{- Parathormon}

Parathormon wirkt im Gegensatz zu den bisher genannten Substanzen primär osteoanabol. Bei pulsativer Verabreichung regt es den Knochenaufbau direkt durch Stimulation der Osteoblasten und indirekt durch die Regulation von Wachstumsfaktoren (z. B. IGF1) an. Ein kontinuierlich erhöhter Parathormonspiegel bei Hyperparathyreodismus injiziert jedoch Osteolyse, indem Osteoklasten aktiviert werden, die den Knochen zur Kalziumimmobilisation abbauen (Canalis et al. 2007). Es wird eine Therapie mit Teriparatid in einer Dosierung von $20 \mu \mathrm{g}$ täglich, subkutan über einen maximalen Zeitraum von 24 Monaten empfohlen (DVO 2009).

\subsubsection{Postmenopausale Hormonersatztherapie (HRT)}

Der progrediente Östrogenmangel nach der Menopause ist der entscheidende Faktor für die Manifestation einer postmenopausalen Osteoporose. Hierbei stellt die Hormonersatztherapie (hormone replacement therapy, HRT) eine effektive und kostengünstige Alternative zur Prävention der Osteoporose dar (Wells et al. 2002).

$\mathrm{Da}$ in den ersten Jahren der Menopause der Knochenmassenverlust am stärksten ist, wird der größte Therapieerfolg mit einem frühzeitigen Therapiebeginn nach Einsetzen der Menopause erzielt. Unter einer Hormontherapie sind verschiedene Nebenwirkungen (Thrombembolien, Insulte, Endometriumkarzinome bei Östrogen-Monotherapie etc.) und resultierenden Kontraindikationen (KHK, Z.n. Thrombembolie, V.a. oder 
Bestehen von Mamma- oder Uteruskarzinom, schwere Lebererkrankung etc.) $\mathrm{zu}$ beachten. Aufgrund dessen wird eine HRT-Therapie heute nur eingeschränkt empfohlen (DVO 2009).

\subsection{Mechanische Stimulation}

Körperliche Belastung gilt als zentrale Säule innerhalb der Osteoporoseprävention und Rehabilitation. Neben einer Reduktion der Sturzhäufigkeit wirkt körperliches Training in vielfältiger Weise auf das Frakturrisiko ein (Kemmler et al. 2003).

Zudem ist erwiesen, dass physiologisch erzeugte mechanische Stimulation, in Form von Körperbewegung, nach der Menopause zu einem verminderten Knochenabbau oder sogar zu einem erhöhten Knochenaufbau führen kann (Dalsky et al. 1988, Smith et al. 1989). Da es jedoch für eine Vielzahl von Osteoporosepatienten aufgrund chronischer Schmerzen, hohem Alter oder Immobilität nicht möglich ist, ausreichend Sport zu betreiben, wurde das Konzept der passiven, nicht-physiologischen mechanischen Stimulation entwickelt.

Eine Form der mechanischen Stimulation ist das Vibrationstraining (wholebody vibration, WBV). Hierbei steht der Patient auf einer Vibrationsplattform, an der die Frequenz, Amplitude und Vibrationsrichtung eingestellt werden kann (Rauch et al. 2010). Vibrationsgeräte besitzen den Vorteil der Benutzerfreundlichkeit, der niedrigen Anschaffungskosten und der einfachen Handhabung für immobile Patienten (Flieger et al. 1998). Ursprünglich wurde das Vibrationstraining zur Vorbeugung von Muskelatrophien und Knochenmassenverlust bei Astronauten entworfen. Dies beruht auf der Theorie der Anpassung des Knochengewebes an seine mechanischen Anforderungen, die erstmalig von Julius Wolff beschrieben und von Harald Frost weiterentwickelt wurde (Wolff 1982). Durch Vibration sollen Dehnreflexe ausgelöst und Alpha-Motoneuronen stimuliert werden, wodurch Muskelkontraktionen entstehen, welche die Leistungsfähigkeit der Muskulatur stärken. Zusätzlich kommt es zu elastischen Verformung des Knochens, das Remodeling und Knochenwachstum induziert (Frost 1997). 
Die Mechanismen der Transduktion eines mechanischen Reizes in eine biologische Antwort sind noch nicht abschließend geklärt. Es wird vermutet, dass durch Verformung der Knochenmatrix hydrostatische Druckunterschiede in den flüssigkeitsgefüllten Knochenkanälchen ausgelöst werden. Die von Matrix ummauerten Osteozyten, deren Zellfortsätze in das Kanalsystem reichen, sind in der Lage diese Druckunterschiede, in Form von Scherkräften wahrzunehmen. Die Stimulation der Osteozytenrezeptoren bewirkt eine Rekrutierung verschieden Zellsignalmoleküle, die folgend Osteoblasten und Osteogenitorzellen aktivieren (Judex und Rubin 2010).

Mechanische Reize, die den Knochenstoffwechsel beeinflussen, lassen sich in hochamplitudige Beanspruchung bei niedrigen Frequenzen (0,5-2 Hertz, $\mathrm{Hz}$ ) oder niedrigamplitudige Belastung bei hohen Frequenzen (10-100 Hz) einteilen (Turner et al. 1995, Rubin et al. 2001). Veröffentlichte Daten haben erwiesen, dass niedrigamplitudige und hochfrequente Stimulation einen größeren anabolen Effekt erzielen kann (Aleyaasin und Harrigan 2008).

Judex et al. testeten an proximalen Tibiae und distalen Femora von ovarektomierten Ratten verschieden Frequenzen aus $(90 \mathrm{~Hz}$ und $45 \mathrm{~Hz}$, $10 \mathrm{~min} / \mathrm{Tag}$ ). Nach 28 Tagen zeigte sich in der Auswertung der Knochenmorphologie der $90 \mathrm{~Hz}$ vibrierten Tiere signifikant erhöhte trabekuläre Knochenvolumina und erhöhte trabekuläre Dicke im Vergleich zur Gruppe der $45 \mathrm{~Hz}$ vibrierten Ratten (Judex et al. 2007). Ein weiterer Vibrationsversuch mit variablen Frequenzen $(17 \mathrm{~Hz}, 30 \mathrm{~Hz}, 45 \mathrm{~Hz})$ an ovarektomierten Ratten, zeigte den größten periostalen Knochenwachstum und die stärkste Hemmung der endokortikalen Resorption bei maximaler Frequenz (Oxlund et al. 2003).

Rubbinacci et al. konnten in einer tierexperimentellen Arbeit mit Ratten zeigen, dass das Fehlen von Östrogen die Empfänglichkeit des Knochens für Vibration erhöhen kann. WBV für zwei Monate mit einer Frequenz von $30 \mathrm{~Hz}$ ergab einen signifikanten anabolen Effekt bei den ovarektomierten Tieren. In der nicht ovarektomierte Kontrollgruppe konnte im Gegensatz dazu kein positiver Effekt erwiesen werden. Die anabole Wirkung hängt dabei von der Vibrationsamplitude ab (Rubbinacci et al. 2008). Die Auswirkung von WBV im wachsenden Skelett bei acht Wochen alten Mäusen untersuchten Xie et al.. Bei einer drei Wochen langen, täglichen Vibration mit $45 \mathrm{~Hz}$, zeigte die 
morphologische Untersuchung des Knochens eine um 30\% reduzierte Osteoklastenaktivität im Vergleich zur Kontrollgruppe bei gleichzeitiger um $30 \%$ erhöhter Knochenbildungsrate (Xie et al. 2006).

Neben Tierversuchen finden sich in der Wissenschaft randominisierte klinische Studien, in denen eine gesteigerte Knochenbildung durch mechanische Stimulation bewiesen wurde. So konnte in einer klinischen Studie gezeigt werden, dass das Vibrationstraining mit $35-40 \mathrm{~Hz}$ zu einer signifikanten Zunahme der Knochendichte im Bereich des proximalen Femurs führte bei 70 postmenopausalen Probandinnen zwischen 58 und 74 Jahren (Verschueren et al. 2004). Eine weitere Studie über 12-monatiger WBV an jungen Frauen führte zu einer erhöhten Knochen- und Muskelmasse im axialen Skelett und den unteren Extremitäten (Gilsanz et al. 2006).

Zusammenfassend deuten die veröffentlichten Studien daraufhin, dass Ganzkörpervibration eine sinnvolle ergänzende nicht-pharmakologische Osteoporosetherapie sein könnte. Dabei ist nicht vollständig erforscht, welche Frequenz, Stimulationszeiträume und Amplitude zu optimalen Ergebnissen führt, wie lange positive Effekte persistieren und ob unerwünscht Nebenwirkungen resultieren (Prisby et al. 2008). 


\section{Material und Methoden}

\subsection{Versuchstiere und Tierhaltung}

Für die Versuche wurden 60 drei Monate alte weibliche Sprague Dawley Ratten verwendet. Die Versuchstiere stammen aus der Tierzucht HarlanWinkelmann (Borchen, Deutschland). Die Ratten wurden fachgerecht in der zentralen Tierexperimentellen Einrichtung (ZTE) des Universitätsklinikum Göttingen von den dort angestellten Tierpflegern und Tierärzten versorgt. Gehalten wurden die Tiere in zwölf Standard-Käfigen (Typ Makrolon ${ }^{\circledR}$ IV) mit jeweils 5 Ratten, bei einer konstanten relativen Luftfeuchtigkeit von $55 \%$ und Umgebungstemperatur von $20 \pm^{\circ} \mathrm{C}$. Die Käfige wurden alle drei Tage desinfiziert und gesäubert. Wasser und Futter wurde nach Belieben bereitgestellt. Der Raum, indem sich die Tiere befanden, wurde mittels Zeitschalter alle zwölf Stunden periodisch beleuchtet. Die Aufsicht über die Experimente, Haltung und Fütterung der Tiere unterlag Dr. med. E. K. Stürmer und Dr. med. D. Seidlova-Wuttke. Sowohl die Tierhaltung, als auch sämtliche mit diesem Projekt verbundenen, Tierversuche wurden vom Regierungsbezirk Braunschweig genehmigt und stimmen mit dem Tierschutzgesetz überein (Genehmigung vom 21/12/06, Az:33.42502-04011/07, Regierungsbezirk Braunschweig).

\subsection{Ablauf des Versuches}

60 Ratten wurden in vier zu untersuchende Gruppen aufgeteilt. Jede Gruppe bestand aus jeweils 15 Tieren. Die eine Hälfte wurde im Alter von drei Monaten bilateral ovarektomiert (OVX, 30 Ratten), die andere Hälfte wurde einer Scheinoperation unterzogen (Eröffnung des Bauchraumes ohne Ovarektomie) und als gesunde Kontrollgruppe verwendet (SHAM, 30 Ratten). Die Tiere wurden daraufhin für zehn Wochen unbehandelt gelassen. In diesem Zeitraum entwickelten die ovarektomierten Ratten Osteoporose (Kalu 1991). 
Nun wurden bei 15 ovarektomierten bzw. SHAM-operierten Tieren eine vertikale Ganzkörpervibration (WBV) mit $90 \mathrm{~Hz}$ und 0,5 mm Amplitude (entspricht einer Beschleunigung von 3,9 g) zwei Mal täglich für je 15 min, 30 Tage lang durchgeführt. Während der gesamten Versuchsreihe wurden die Tiere wöchentlich gewogen und später die Tiergewichte analysiert. Zusätzlich wurden fünf Tage vor Beginn der Vibration alle 60 Ratten an den Tibiae osteotomiert, um in weiteren experimentellen Arbeiten die Auswirkung von mechanischer Stimulation auf die Frakturheilung zu erforschen (Stürmer et al. 2010, Utesch 2016).

Nach Tötung der Tiere wurden die Lendenwirbelkörper (LWK) präpariert und zur Analyse der Vibrationseffekte verwendet. An den I. LWK jedes Tieres erfolgte die Durchführung der mikroradiographischen Untersuchungen (siehe 2.4). Hierbei wurden die morphologischen Eigenschaften des Knochens ermittelt. Anschließend wurde an den IV. LWK die biomechanische Festigkeit mit Hilfe eines mechanischen Bruchtests (siehe 2.5) untersucht. Ergänzend wurden die II. LWK verascht (siehe 2.6) und daraus die mineralische Knochendichte der Knochen berechnet.

Tabelle 5: Gruppenaufteilung und Behandlung der Tiere

\begin{tabular}{c|c|c}
\hline Gruppen & $\begin{array}{c}\text { Anzahl der } \\
\text { Tiere/Gruppe }\end{array}$ & Behandlung \\
\hline OVX Vib. & 15 & $\begin{array}{c}\text { ovarektomiert und } \\
\text { vibriert }\end{array}$ \\
\hline OVX & 15 & ovarektomiert \\
\hline SHAM Vib. & 15 & intakt und vibriert \\
\hline SHAM & 15 &
\end{tabular}

\subsubsection{Ovarektomie der Versuchstiere}

Die Narkose wurde mit einer kurzen $\mathrm{CO}_{2}$-Inhalation eingeleitet und folgte mit einer intraperitonealen Applikation von 62,5 mg/kg Körpergewicht (KG) Ketamin (Hostaket ${ }^{\circledR}$, Fa. Hoechst) und $7,5 \mathrm{mg} / \mathrm{kg} \mathrm{KG} \mathrm{Xylazin} \mathrm{(Rompun®,}$ 
Bayer). Zunächst wurden die Tiere an den lateralen Partien zwischen Rippenbogen und Hinterläufen rasiert und desinfiziert. Nach Inzision der Haut folgte die vorsichtige Präparation bis zum Peritoneum. Nachdem die Bauchhöhle geöffnet wurde, wurden die Ovarien aufgesucht, die Tubae uterinae ligiert und die Ovarien abgesetzt. Zuletzt nähte man die beiden Hautwunden mit Vicryl-Fäden zu. Um einem möglichen Flüssigkeitsdefizit der Tiere vorzubeugen, wurde jeder Ratte nach der Operation ein $\mathrm{NaCl}$-Depot von $3 \mathrm{ml}$ subcutan verabreicht. Die Tiere wurden bis zum Ende der Vollnarkose überwacht (Erren 2007).

\subsubsection{Osteotomie der Versuchstiere}

Alle 60 Ratten wurden zehn Wochen nach Ovarektomie einer bilateralen transversen Osteotomie der Tibiae in den Metaphysen unterzogen. Die rechte und linke Tibia, der mit Ketamin/Xylazine anästhesierten Ratten, wurde mit einer Ultraschallsäge (Piezosurgery®, mectron medical technology, Carasco, Italy) $7 \mathrm{~mm}$ distal des Knies osteotomiert. Daraufhin wurde eine Tförmige fünfloch-Titanplatte (57-05140, Stryker Trauma, Selzach, Switzerland) an der ventro-lateralen Seite der Tibia befestigt. Die Fixation der Platte wurde mit vier Schrauben, in Form einer Überbrückungstechnik, durchgeführt. Während der Operation erhielten die Ratten 5 mg Decentan subcutan (Merck, Darmstadt, Germany), 4 mg Rimadyl (Pfizer, Karlsruhe, Germany) pro Kg Körpergewicht. Postoperativ wurde Rimadyl 2 × pro Tag über zwei Tage injiziert. Die Ergebnisse dieses Versuches wurden im Rahmen einer anderen Studie ausgewertet (Utesch 2016).

\subsubsection{Ganzkörpervibration der Versuchstiere}

Fünf Tage nach der Osteotomie, wurde die Hälfte der ovarektomierten und die Hälfte der SHAM-operierten Ratten (OVX Vib. und SHAM Vib.) einer vertikalen Ganzkörpervibration, mit einer Frequenz von $90 \mathrm{~Hz}$ und einer Amplitude von 0,5 mm unterzogen. Die beiden anderen Hälften der Ratten wurden nicht vibriert (OVX und SHAM). Jeweils zehn Ratten wurden in einen weichen Plastikkäfig, der auf einer Vibrationsplatte befestigt war, gegeben und zwei Mal täglich, 7x/Woche 15 min lang, für 30 Tage vibriert. Die Tiere konnten während der Vibrationsbehandlung frei herumlaufen, wobei darauf 
geachtet wurde, dass sich jede Ratte im Vierfußstand positionierte, sodass der Effekt der Vibration nicht abgeschwächt wird (Utesch 2016).

Das neu entwickelte Vibrationsgerät (Vibra Maschinenfabrik Schultheis GmbH\&Co, Offenbach, Deutschland) bestand insgesamt aus einer Vibrationsplatte, zwei Wechselstrommotoren (Drehstrom-Vibrationsmotor Typ HVL/HVE) und einem Kraftsensor, mit dem die Frequenz gesteuert wurde. Um die Ratten während der Vibrationsphase auf der Platte zu halten, wurde ein Plastikkäfig $\left(50 \times 50 \times 25 \mathrm{~cm}^{3}\right)$ entwickelt. Dieser wurde mit dem Vibrationsgerät so fixiert, dass der weiche Boden des Käfigs auf der festen Oberfläche der Platte haftete (siehe Abbildung 1).

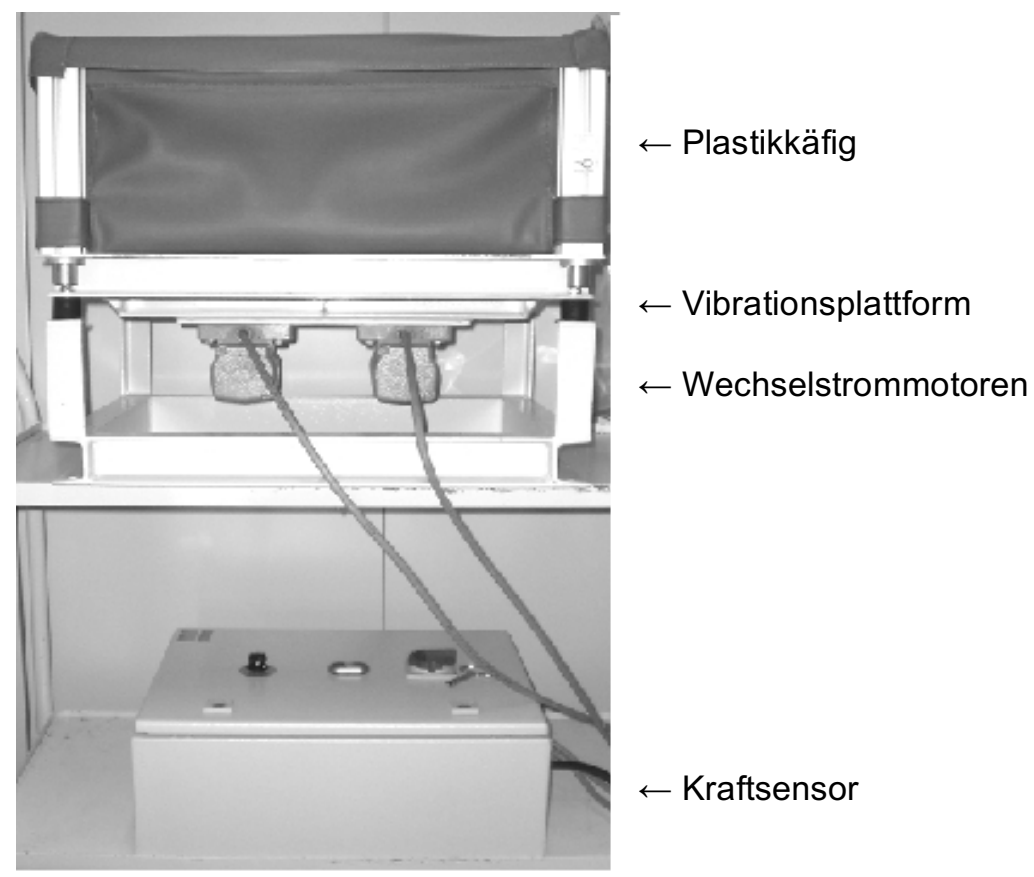

Abbildung 1: Darstellung des Vibrationsgeräts (Stürmer et al. 2010)

\subsubsection{Futteraufnahme und Gewicht der Versuchstiere}

Während des Experimentes erhielten die Ratten standardisierte Basisnahrung (Ssnif Spezialdiäten $\mathrm{GmbH}$, 10-mm-Pellets, Soest, Deutschland) und wurden wöchentlich gewogen. Alle Tiere hatten beliebigen Zugang zu Futter und Wasser und konnten sich frei im Käfig bewegen. Das Restfutter wurde wöchentlich gewogen und auf $1500 \mathrm{~g}$ aufgefüllt. Die tägliche Nahrungsaufnahme eines Tieres konnte somit berechnet werden. 


\subsubsection{Präparation der Wirbelkörper}

Die Tötung der Tiere erfolgte 17 Wochen nach Beginn des Projektes in $\mathrm{CO}_{2-}$ Narkose durch Dekapitation. Es wurde paraspinal entlang des Rückens der Ratten die Haut inzidiert und Muskeln und Sehnenansätze, soweit notwendig, vorsichtig entfernt. Der Verlauf der Lendenwirbelsäule ließ sich durch Aufsuchen der kaudalen Rippenansätze und des Os sacrum gut darstellen. Die Wirbelsäule wurde daraufhin unterhalb des 12. Brustwirbelkörpers beziehungsweise oberhalb des Kreuzbeines mit einer Zange scharf durchtrennt (siehe Abbildung 2). Im weiteren Verlauf wurden die einzelnen Wirbelkörper entlang der Disci intervertebrales mit einem Skalpell separiert und von Haut, Muskeln und Sehnenreste frei präpariert. Anschließend wurden die einzelnen Lendenwirbelkörper bis zur weiteren Verwendung in einem Plastikröhrchen bei $-20 \mathrm{C}^{\circ}$ eingefroren. Zusätzlich wurden Tibiae, Femora und Muskeln entfernt und für weitere Versuche verwendet (Stürmer et al. 2010, Utesch 2016).

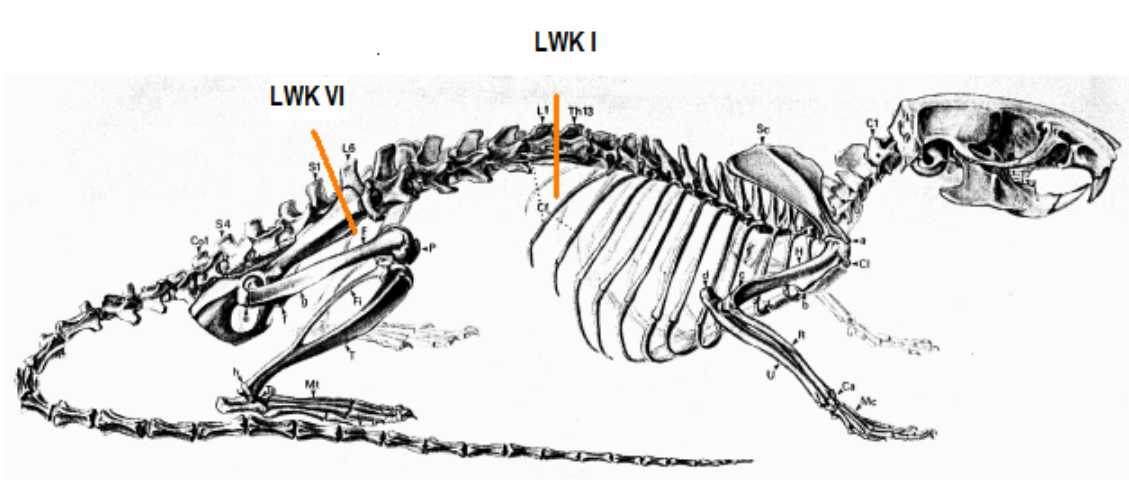

Abbildung 2: Anatomie einer Ratte (Hebel et al. 1986, S 10.)

\subsubsection{Berechnung des Wirbelkörpervolumens}

Für weitere Auswertungen wurde das Volumen der Wirbelkörper bestimmt. Die Corpora vertebrae der präparierten LWK wurden mit einer Schieblehre manuell vermessen und das jeweilige Volumen (V) als Zylinder aus dem Produkt von Höhe (h) und Durchmesser $\left(r^{2}\right)$ wie folgt berechnet (Döll 2010).

$$
V=\pi h r^{2}
$$




\subsection{Serumanalyse}

Nach Durchführung der Dekapitation wurden aus den cervikalen Gefäßen der Tiere Blutproben entnommen (ungefähr $0,5 \mathrm{ml}$ ). Es wurde Osteocalcin, ein Marker für den Knochenaufbau, und alkalische Phosphatase, ein Marker für den Knochenabbau, ermittelt. Das Blut wurde zunächst zentrifugiert und das Serum bei $-20^{\circ} \mathrm{C}$ aufbewahrt. Der Hormonwert von Osteocalcin wurde später mittels Chemolumineszenz-Immunoassay bestimmt. Die Konzentration des Enzyms alkalische Phosphatase wurde unter Verwendung eines KalometrieAssays gemessen (Roche- Labordiagnostik, Mannheim, Deutschland). Die Messungen wurden in der Abteilung für Klinische Chemie (Universitätsmedizin Göttingen) durchgeführt.

\subsection{Mikroradiographie}

\subsubsection{Histologische Präparation und Anfertigung der Mikroradiographien}

Die ersten LWK der Tiere wurden zur Entfettung und Entwässerung einer Alkoholreihe zugeführt. Die Knochen wurden zunächst in $40 \%$ igem, 70\%igem, $80 \%$ igem und letztlich 100\%igem Alkohol für insgesamt sieben Tage gelagert. Es folgte die Einlagerung in einem 1:1- Gemisch von 100\%igem Ethanol und Methylmethacrylat, bis die Präparate zu Kunststoffblöcken polymerisierten und sich vollständig aushärteten (Merck). Die Aushärtung der Kunststoffe dauert ca. 21 Tage. Die eingebetteten LWK wurden sagittal mit einer diamant-beschichteten Säge in 100 $\pm 10 \mu \mathrm{m}$ dünne Scheiben geschnitten (Leica SP Innenlochsäge-Mikrotom, Bensheim, Deutschland). Hierfür wurde ein $350 \mu \mathrm{m}$ breites Sägeblatt verwendet.

Vier Sagittalschnitte, die aus der Mitte der einzelnen Corpora vertebrae entstanden, wurden für die Mikroradiographie verwendet. Diese wurden im Faxitron-Röntgengerät (Hewlett Packard, San Diego, USA, Modell-Nr. 43855A) auf langsamen Industriefilm (Kodak SR Typ 45) geröntgt. Die Röhrenspannung betrug $10 \mathrm{kV}$ bei einer Belichtungszeit von $3 \mathrm{~min}$. Nach Fixierung der entstandenen Mikroradiographien wurden diese in willkürlicher Reihenfolge in Ordnern archiviert (Stürmer KM 1980). 


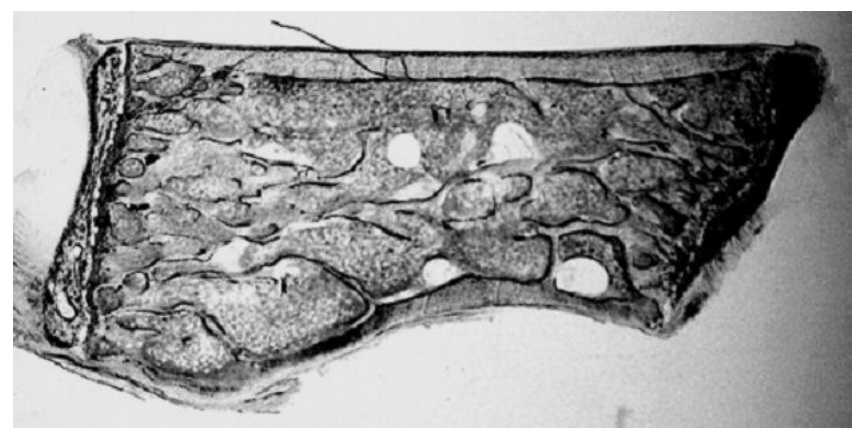

Abbildung 3: Fotografierter Sagittalschnitt des Corpus vertebrae

\subsubsection{Digitalisierung der Mikroradiographien}

Für die spätere Analyse der Mikroradiographien wurden die vier zentralen Sagittalschnitte mithilfe eines Makroskopes, einer digitalen Kamera und einer Software digitalisiert. Es wurde ein Makroskop (Leica Stereomakroskop MZ 75) verwendet, dessen verschiedene Belichtungsmöglichkeiten durch Vorversuche für die vorliegenden Mikroradiographien optimal ausgewählt und konstant angewandt wurden. Hierfür wurden manuell die Helligkeit und die Lichttemperatur eingestellt. Die mechanische Blende der Kamera wurde auf eine definierte Schalterposition „B“ eingestellt, sodass eine geringe Helligkeit erreicht wurde $(A=$ geringste Helligkeit, $E=$ maximale Helligkeit). Die Temperatur der Halogenlampe musste entsprechend angepasst werden, da die Schnittdicke und damit die Helligkeit der angefertigten Präparate minimal variierte. Hierbei wurde ein festgelegter Bereich der Lichttemperatur von 2900 $\mathrm{K}$ bis $3000 \mathrm{~K}$ eingehalten. Nun musste das unter dem Makroskop entstandene Bild mit Hilfe einer Kamera (Leica DC Twain Setup 300F), die direkt mit einem Computer (Intel Pentium 4; 2,6 GHz) verbunden war, eingelesen werden. Damit die Objekte in einer einheitlichen Größe auf dem Monitor abgebildet wurden, war das Objektiv stets auf 1,0 eingestellt. Zur weiteren Standardisierung musste die während des Einlesens von der Software benutzte Belichtungszeit immer auf $345 \mathrm{~ms}$ eingestellt werden (Stürmer KM 1980). Das so digitalisierte Bild konnte nun mit einer speziell konzipierten Software (Leica Quantimet QWin 2003) bearbeitet und nach einem standartisierten Algorithmus ausgewertet werden (Sehmisch et al. 2009a, b). 


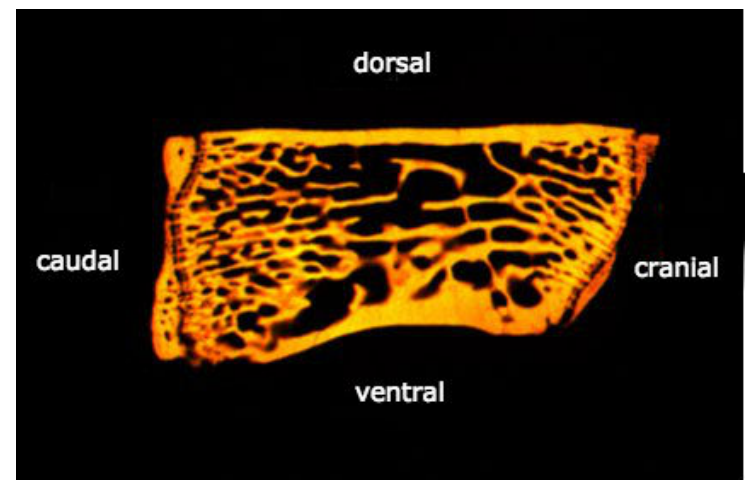

Abbildung 4: Digitalisierter Sagittalschnitt des Corpus vertebrae

\subsubsection{Auswertung der Mikroradiographien}

Die Bearbeitung und Analyse der digitalisierten Sagittalschnitte der Rattenwirbel erfolgte nun mit dem in 2.4.2 erwähnten Computerprogramm. Hierzu wurden folgende Schritte manuell in einer bestimmten Reihenfolge bearbeitet. Zunächst wurden die mikroradiographischen Schnitte detektiert (siehe 2.4.3.1). Anschließend wurden die Gesamtfläche und die endostale Fläche des Corpus vertebrae ermittelt (siehe 2.4.3.2, 2.4.3.3). Daraufhin erfolgte die Berechnung der Kortikalisfläche (siehe 2.4.3.4).

\subsubsection{Graudetektion}

Die Graudetektion diente zur exakten Bestimmung der tatsächlichen Knochenanteile der Mikroradiographie. Die von der Software detektierten mineralisierten Strukturen färbten sich blau an. Der Untersucher konnte die Anfärbung manuell korrigieren, wobei die Detektion einen definierten Bereich von 50-90 nicht verlassen durfte (siehe Abbildung 5).
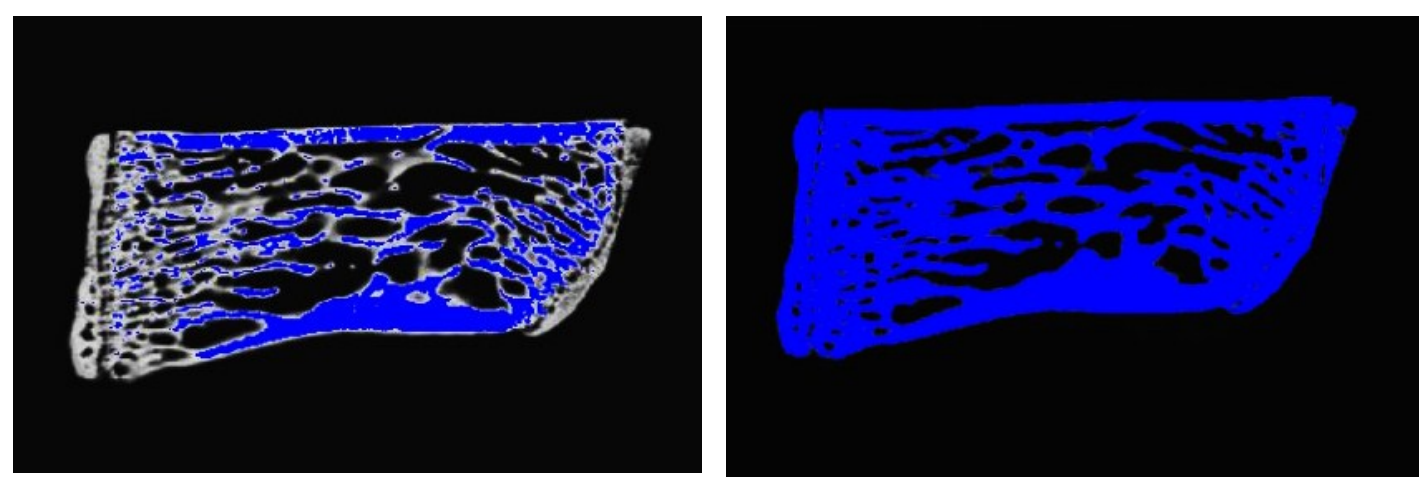

Abbildung 5: Graudetektion 


\subsubsection{Ermittlung der Gesamtfläche des Wirbelkörpers}

Zur Bestimmung der Gesamtfläche des LWK wurde ausschließlich der Corpus vertebra betrachtet. Der mikroradiographierte Wirbelkörperschnitt lässt sich vereinfacht in eine kompakte weniger strahlendurchlässige äußere Knochenschicht (Kortikalis) und eine innen liegende, balkenartig aufgebaute, Knochensubstanz (Trabekel) einteilen. An den kranial und kaudalen Enden des Schnittes sind die Epiphysenfugen sichtbar (siehe Abbildung 4). Der Untersucher musste nun eine $2 \mathrm{~mm}$ dicke Linie um den äußeren Rand der Kortikalis führen. Die Epiphysenfugen dienten als kraniale und kaudale Begrenzung der Gesamtfläche des Wirbelkörpers. Innerhalb dieser Grenzlinie konnte die Software, mit Hilfe der vorausgegangenen Graudetektion, die Gesamtfläche aller knöchernen Strukturen ausmessen (siehe Abbildung 6).
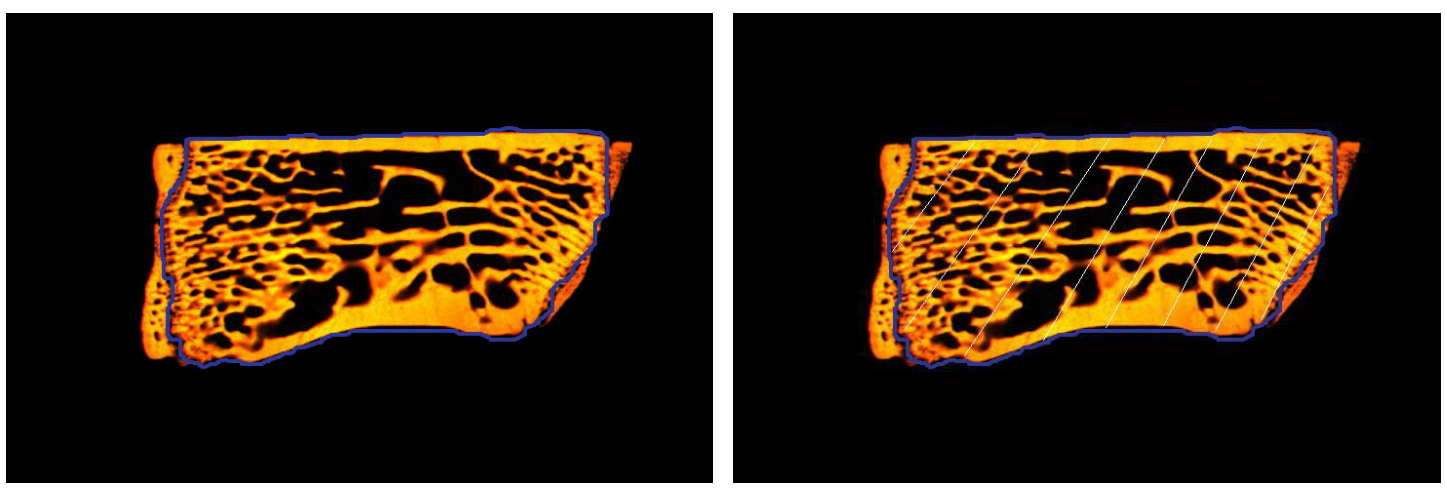

Abbildung 6: Gesamtfläche des Corpus vertebra

\subsubsection{Ermittlung der endostalen Gesamtfläche}

Um die Trabekelfläche von der kortikalen Knochenstruktur abzugrenzen, musste die endostale Gesamtfläche mittels Software berechnet werden. Hierzu zog der Untersucher eine weitere Linie entlang der inneren Knochenhaut, dem Endost. Die Epiphysenfugen fungierten hierbei als äußere Begrenzungen. Zur Unterscheidung der trabekulären und nicht-trabekulären Anteile innerhalb dieser begrenzten Fläche diente wiederum die Graudetektion (siehe Abbildung 7). 

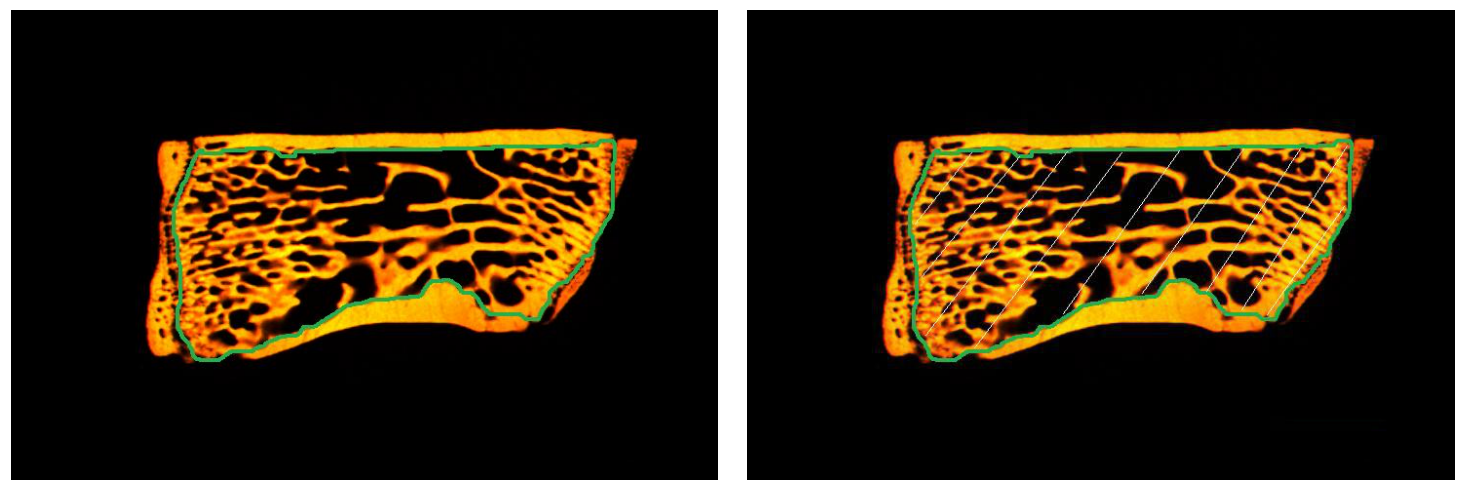

Abbildung 7: Endostale Gesamtfläche

\subsubsection{Berechnung der Kortikalisfläche}

Zur Berechnung der kortikalen Fläche musste das Computerprogramm die in 2.4.3.3 gemessene Trabekelfäche von der Gesamtfläche abziehen.

\subsubsection{Messparameter der Mikroradiographie}

Folgende Messparameter wurden entsprechend der standardisierten Nomenklatur der ASBMR (American Society for Bone and Mineral Research) mit Hilfe der in 2.4.3 beschriebenen Analyseschritte ermittelt (Parfitt et al. 1987, Sehmisch et al. 2009b).

Tabelle 6: Messparameter der Mikroradiographie

\begin{tabular}{l|c|l}
\hline \multicolumn{1}{c|}{ Messparameter } & Maßeinheit & \multicolumn{1}{c}{ Definition } \\
\hline $\begin{array}{l}\text { Kortikale } \\
\text { Knochenflächendichte }\end{array}$ & $\%$ & $\begin{array}{l}\text { Kortikaler Anteil der } \\
\text { Knochengesamtfläche }\end{array}$ \\
$\begin{array}{l}\text { Dichte } \\
\text { Trabekelkreuzungen }\end{array}$ & $\mathrm{n} / \mathrm{mm}^{2}$ & $\begin{array}{l}\text { Relative Anzahl der Kreuzungspunkte } \\
\text { von Trabekelarmen pro mm² }\end{array}$ \\
$\begin{array}{l}\text { Anzahl } \\
\text { Trabekelkreuzungen } \\
\text { absolut }\end{array}$ & $\mathrm{n}$ & $\begin{array}{l}\text { Absolute Anzahl der Kreuzungspunkte } \\
\text { von Trabekelarmen }\end{array}$ \\
$\begin{array}{l}\text { Trabekuläre } \\
\text { Knochenfläche }\end{array}$ & $\mathrm{mm} \mathrm{m}^{2}$ & $\begin{array}{l}\text { Summe der Knochenfläche aller } \\
\text { Trabekel innerhalb der endostalen } \\
\text { Gesamtfäche }\end{array}$ \\
Mittlere Trabekeldicke & $\mu \mathrm{m}$ & $\begin{array}{l}\text { Durchschnittliche Dicke aller Trabekel } \\
\text { innerhalb der absoluten Trabekelfläche }\end{array}$ \\
\hline
\end{tabular}




\subsubsection{Eichung der Software}

Die in 2.4.3 beschriebenen Auswertungsschritte sind benutzerdefiniert. Um die Messgenauigkeit des Untersuchers zu bestimmen, wurden 5 LWK mit jeweils 3 Sagittalschnitte zufällig ausgewählt und alle Messparameter an zwei aufeinander folgenden Tagen bestimmt. Dabei musste eine Schwankungsbreite $+/-5 \%$ eingehalten werden.

\subsection{Biomechanischer Kompressionstest}

Am intakten IV. LWK wurde eine biomechanische Testung durchgeführt, um die Widerstandsfähigkeit des osteoporotischen Knochens gegen einwirkende mechanische Kräfte zu analysieren. Zur Bestimmung der Festigkeit der Wirbel, wurde die erreichbare Maximalkraft ermittelt und das Auftreten erster trabekulärer Mikrofrakturen untersucht. Hierzu wurden die Wirbelkörper mit Hilfe einer Testmaschine (Typ 145660 Z020/TND Zwick/Roell, Ulm, Germany) und einer Haltevorrichtung in axiale Richtung komprimiert (Stürmer et al. 2006). Die hierbei gewonnenen Werte, wurden mit einer bestimmten Software („testXpert"-Software) in einen Computer eingelesen und an einem Graphen abgeleitet (Sehmisch et al. 2009a, Erren 2007).

\subsubsection{Aufbau der Bruchvorrichtung}

In vorherigen Versuchen wurde speziell für diesen Test eine Haltevorrichtung für die Wirbelkörper entwickelt, getestet und optimiert. Die aus Aluminium errichtete Apparatur wurde möglichst genau an die Anatomie der Wirbelkörper angepasst, sodass der Wirbelkörper optimal stabilisiert werden konnte. Die Vorrichtung bestand aus einer $4 \times 3 \mathrm{~cm}$ messenden, angewinkelten stabilen Basis, einer in $45^{\circ}$ - Neigung angefertigten Auflagefläche und einer Schleuse (siehe Abbildung 9). Die Auflagefläche entsprach den durchschnittlichen, gemessenen Neigungen der kranialen Deckplatte des LWK IV. Der Wirbelkörper wurde so platziert, dass der Processus spinosus mit einer Stellschraube in der einseitig geöffneten Schleuse arretiert werden konnte. Hierdurch war der LWK in der Apparatur gewissermaßen gefangen und konnte während der Kompression nicht verrutschen. Auf eine echte Fixierung des Wirbels wurde verzichtet, damit 
diesem während der Belastungsphase des Tests keine zusätzliche Widerstandskraft verliehen wurde. Um die axiale Kompression durchführen zu können, benötigte man zusätzlich ein Gegenstück zur Basis. Dies stellte die Testmaschine mit einem Stempel dar, der wie die Auflagefläche eine $45^{\circ}$ Neigung aufwies. Basis und Stempel hatten einen Durchmesser gemäß den Flächen der Grund- und Deckplatten der Wirbelkörper. Hierdurch konnte eine möglichst ideale Axialkompression bei minimaler Reibung zwischen Material und Knochen gewährleistet werden.
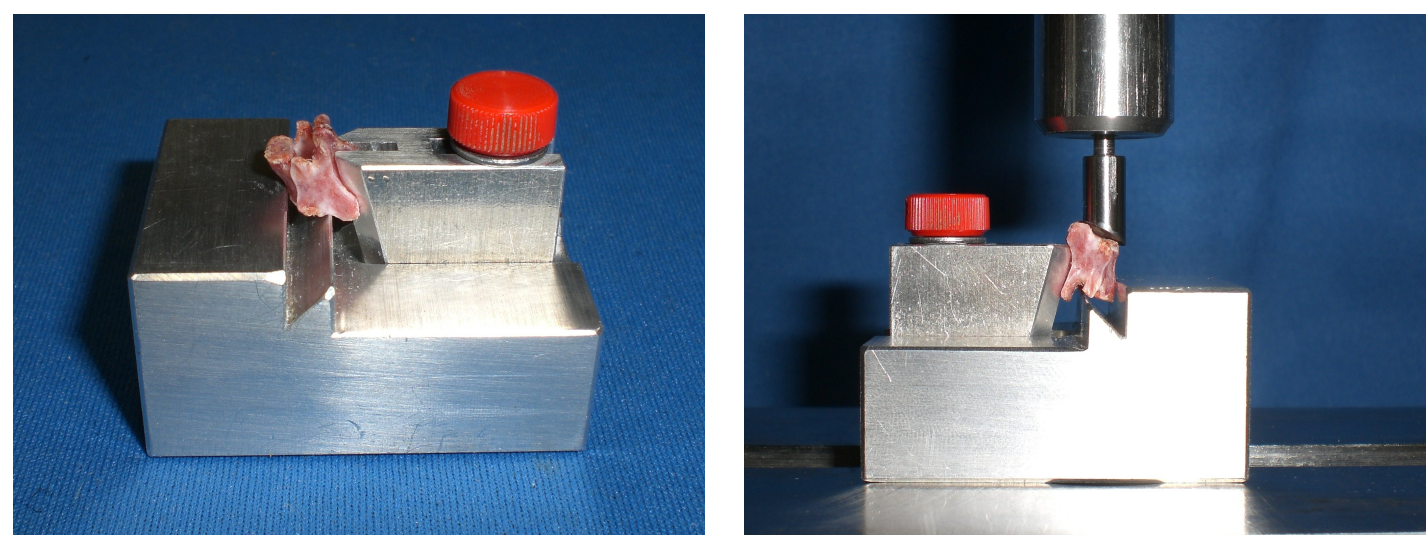

Abbildung 9: Bruchvorrichtung mit Lendenwirbelkörper

\subsubsection{Durchführung des Kompressionstests}

Nachdem der LWK IV, wie in 2.5.1 beschrieben, positioniert war, begann die Durchführung des Kompressionstests. Die Zwick-Testmaschine fuhr den Stempel axial nach unten, bis eine Vorkraft von $1 \mathrm{~N}$ erreicht war und Kontakt zur kaudalen Endplatte des Wirbelkörpers hergestellt war. In dieser Einstellung stoppte der Test automatisch und der Untersucher konnte die Position des Stempels an der Endplatte des Wirbelkörpers visuell überprüfen und, wenn es notwendig war, manuell korrigieren. Die Geschwindigkeit, mit der die Testmaschine den Stempel nun senkte, betrug $50 \mathrm{~mm} / \mathrm{min}$. Die aufzuwendende Kraft, um den Corpus vertebrae zu komprimieren, wurde alle 0,1 mm mithilfe der „testXpert“-Software bestimmt und in den Computer eingelesen. Der Messbereich der mechanischen Kräfte reichte von $2 \mathrm{~N}$ bis $500 \mathrm{~N}$ bei einer relativen Genauigkeit von 0,2 \% bis 0,4\%. Der Test endete automatisch, wenn eine Kraftgrenze von $500 \mathrm{~N}$ erreicht wurde oder der 
Wirbelkörper um 3,0 mm komprimiert wurde (Stürmer et al. 2006, Sehmisch et al. 2009a, Erren 2007).

\subsubsection{Messparameter des biomechanischen Kompressionstests}

Maximalkraft:

Die Maximalkraft (Fmax) ist die größtmögliche Kraft, gegen die der Wirbelkörper noch standhalten kann.

Yield Load:

Die Yield Load $(\mathrm{YL})$ stellt den Übergang der elastischen zur plastischen Verformung während der Kompression dar und repräsentiert damit, die ersten Mikrofrakturen des trabekulären Knochenmaterials. Die Stelle, an der die Steigung ihre Linearität verliert und niedrigere Werte annimmt, wird als Yield Load bezeichnet. Um diesen zu definieren, wurden aus den Werten des linear ansteigenden Graphen die Regressionsgerade und dessen Standardabweichung berechnet. Der Punkt, an dem der Graph den Bereich der doppelten Standardabweichung der Regressionsgeraden verliert, wird als Yield Load bezeichnet (Stürmer et al. 2006).

\section{Steigung:}

Die Steigung ist ein Maß für die Steilheit einer Kurve. Sie wurde an einer beliebigen Stelle innerhalb des linearen Anteils des Graphen ausgewertet und entsprach der elastischen Verformung des LWK.

\subsubsection{Kraft-Weg-Diagramm}

Die Auswertung der eben beschriebenen Messparameter erfolgte an einem Graphen, den die "testXpert"-Software anhand der gewonnenen Daten erstellte (siehe Abbildung 10). Die x-Achse des Diagramms zeigte die Kompression $(\mathrm{mm})$ der Wirbelkörper an, während die y-Achse die hierfür benötigte Kraft $(\mathrm{N})$ aufwies. Die ermittelte Kurve verläuft in allen Tests in einer bestimmten Form, wie es schon in anderen Bruchtests mit Ratten-Tibiae beschrieben wurde (Stürmer et al. 2006). Zu Beginn des Kompressionstests steigt der Graph linear an. Dies entspricht einer elastischen Verformung des Wirbelkörpers. Hierbei treten noch keine irreversiblen strukturellen Veränderungen des Knochens auf. Innerhalb des linearen Graphen- 
Abschnittes wurde die Steigung (siehe 2.5.3) berechnet. Im weiteren Verlauf nähert sich die Kurve langsam der x-Achse, mit abnehmender Steigung an, bis sie ihren Maximalwert (Fmax) erreicht hat. Dies zeigt die Phase der plastischen Verformung des Wirbelkörpers auf, die mit trabekulären Mikrofrakturen einhergeht. Der Übergang zwischen diesen beiden Phasen wurde als Yield Load (YL) definiert (siehe 2.5.3). Nachdem die Kurve ihren Höhepunkt erreicht hat, nimmt sie einen unregelmäßig absteigenden Verlauf an. Dieser Abschnitt stellt eine makroskopisch sichtbare, trabekuläre und kortikale Fraktur des Wirbelkörpers dar.

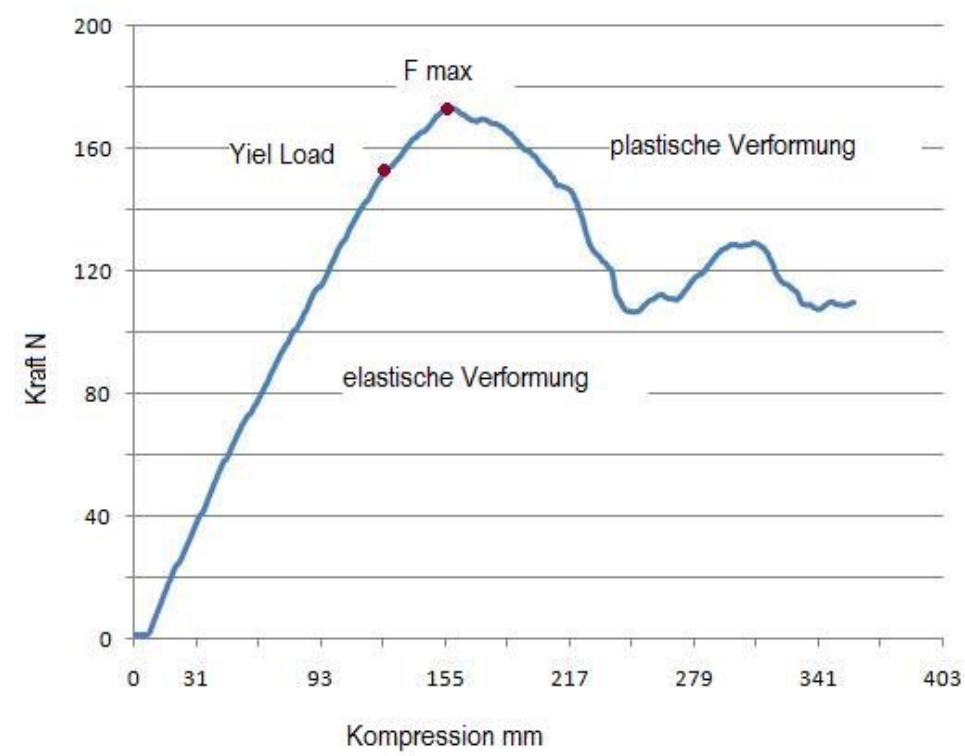

Abbildung 10: Kraft-Weg-Diagramm (eigene Darstellung)

\subsubsection{Evaluation des Kompressionstests}

Für die Evaluation des biomechanischen Kompressionstests wurden zunächst die LWK IV und V von 10 Ratten, die der Größe und Gewicht den im Versuch verwendeten Tieren entsprachen, untersucht. Nach Durchführung des biomechanischen Kompressionstests wurden jeweils die Parameter Maximalkraft, Yield Load und Steigung bestimmt und einem Rechts-LinksVergleich unterzogen. Abweichung von 15\% (+/-3\%) wurden als korrekt betrachtet (Budsberg et al. 1993). 


\subsection{Veraschung}

Neben den mikroradiographischen Untersuchungen und der biomechanischen Testung wurde der anorganische und organische Anteil der Rattenwirbelkörper durch Erzeugung eines Glührückstandes mittels Veraschung bestimmt. Diese Untersuchung wurde in der Abteilung für allgemeine Hygiene und Umweltmedizin der Universität Göttingen durchgeführt.

Hierzu wurden die entnommenen II. LWK aufgetaut und die Gesamtmasse $\left(m_{1}\right)$ zunächst mit einer Waage (Sartorius Basic Ba1109 H94) bei einer Genauigkeit von 0,00001 g analytisch gewogen. Anschließend wurden neun zufällig ausgewählte LWK in Porzellantiegel gegeben und in einem Muffelofen (220 Volt, 900 Watt, Klees) bei $750^{\circ} \mathrm{C}$, 48 Stunden lang, verascht. Zur Abkühlung wurden die LWK in einen Exsikkator über Kieselgel gestellt, um das Entstehen von Kondensationsfeuchtigkeit zu verhindern (siehe Abbildung 11). Nach Abkühlung bis auf Raumtemperatur wurde die Masse $\left(m_{2}\right)$ der LWK ein zweites Mal durch analytisches Wiegen bestimmt. Die Masse $\left(m_{2}\right)$ entspricht der anorganischen Knochensubstanz des Wirbelkörpers.

Anhand der Masse der Knochenproben, die vor und nach der Veraschung ermittelt wurde, konnte mit folgender Formel der prozentuale Anteil organischer und anorganischer Substanz an der Knochenmasse berechnet werden:

- $\%$ organische Substanz $=\left(m_{1} m_{2}\right) 100 / m_{1}$

- $\%$ anorganische Substanz $=100-\%$ organische Substanz

Anschließend wurde die Knochenmineraldichte (BMD) in $\mathrm{g} / \mathrm{mm}^{3}$ mit entsprechender Formel berechnet:

- $B M D=m_{2} /$ Volumen

Die Bestimmung des Wirbelkörpervolumens für die Auswertung der BMD wurde mittels Mikro-Computertomographie berechnet (Sehmisch et al. 2009b). 


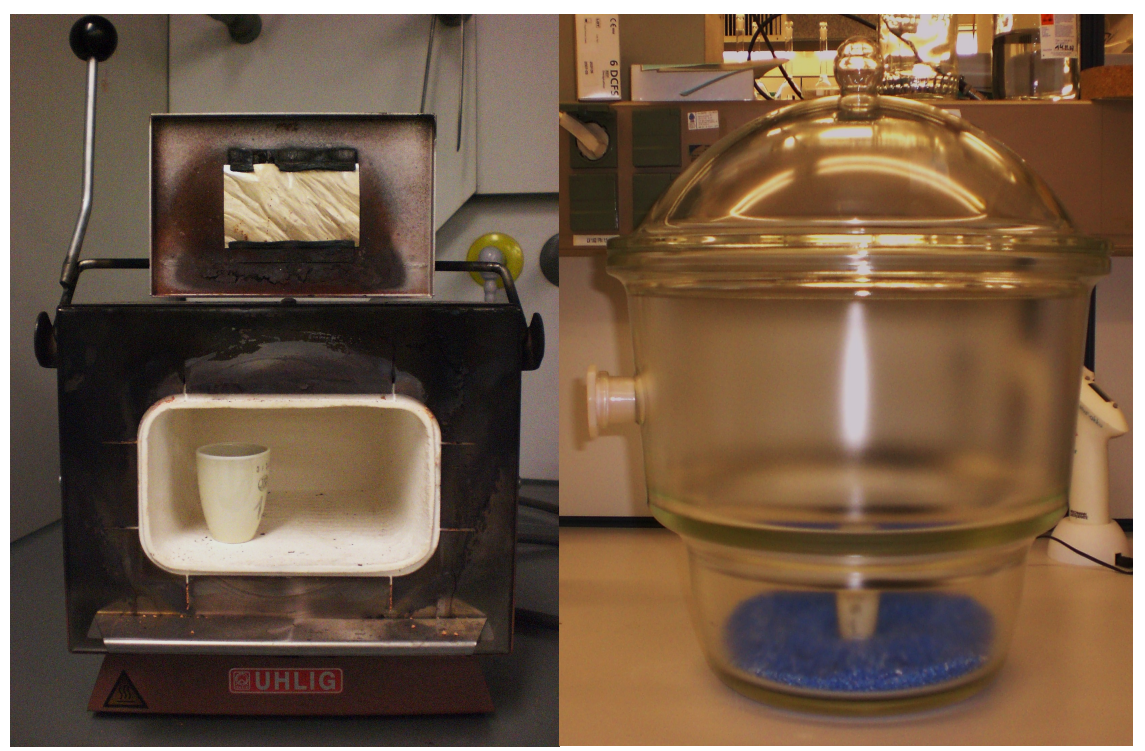

Abbildung 11: Muffelofen und Exsikkator

\subsection{Statistische Auswertung}

Anhand der Software Graph Pad Prism (Version 4.00a, April 2003, Graph Pad Software Inc., San Diego, USA) wurden alle statistischen und graphischen Auswertungen durchgeführt.

Die bei den Versuchen ermittelten Daten wurden zunächst mit Hilfe einer twoway ANOVA auf signifikante Unterschiede zwischen den einzelnen Gruppen untersucht.

Im Anschluss daran diente ein Tukey-Kramer-post-hoc-Test dazu die Ergebnisse genauer zu identifizieren. Als Signifikanzniveau wurde $\alpha \leq 0,05$ bestimmt (Sehmisch et al. 2009b). 


\section{Ergebnisse}

Im Folgenden werden die Ergebnisse der einzelnen Messparameter dargestellt. Die tabellarische Auflistung fasst alle gemessenen Mittelwerte (MW) und Standardabweichungen (SD), sowie die ausgewerteten Unterschiede zwischen den einzelnen Gruppen (OVX vs. SHAM und Vib. vs. nicht Vib.) zusammen. Die Gruppe Vib. stellt alle vibrierten Tiere dar (SHAM Vib. + OVX Vib.). Die Gruppe nicht Vib. bezeichnet alle nicht vibrierten Tiere $(\mathrm{SHAM}+\mathrm{OVX})$.

Für die mittels two-way ANOVA und Tukey-Kramer post-hoc Test berechneten Unterschiede, wurde ein $p \leq 0,05$ als "signifikant" und ein $p \leq 0,0001$ als "hochsignifikant" bestimmt. Die graphische Darstellung findet im Säulendiagramm statt, mit Markierung des Signifikanzniveaus wie folgt: * $p \leq$ 0,05 vs. OVX und $\# p \leq 0,05$ vs. nicht Vib.

\subsection{Ergebnisse der Messung der Tiergewichte und der Uterusgewichte}

Zu Beginn des Versuchs hatten alle Tiere ein ähnliches Körpergewicht. Die Ovariektomie führte zu einer signifikanten Gewichtszunahme im Vergleich zur Kontrollgruppe. Nach Ganzkörpervibration hatten die OVX-Tiere ein im Durchschnitt um 9,4 g und die SHAM-Tiere ein um 4,2 g geringeres Gewicht, infolge des Trainingseffektes. Das Körpergewicht der nicht vibrierten Tiere stieg durchschnittlich um 4,1 g bei SHAM-Tieren und um 4,4 $\mathrm{g}$ bei OVXTieren.

Das durchschnittliche Uterusgewicht der SHAM Tiere war signifikant höher im Vergleich zur den OVX-Tieren, wogegen Vibration keinen signifikanten Effekt auf das Uterusgewicht zeigte. Die Daten des Gewichtsverlaufs wurden in weiteren Studien verwendet (Stürmer et al. 2010, Utesch 2016). 
Tabelle 7: Ergebnisse der Messung der Tiergewichte und der Uterusgewichte (Angabe in $\mathrm{MW} \pm \mathrm{SD}$ und $\mathrm{p}$-Werte)

\begin{tabular}{|l|c|c|c|c|l|l|}
\hline Parameter & SHAM & SHAM Vib. & OVX & OVX Vib. & $\begin{array}{l}\text { OVX vs. } \\
\text { SHAM }\end{array}$ & $\begin{array}{l}\text { Vib. vs. } \\
\text { nicht } \\
\text { Vib. }\end{array}$ \\
\hline Gewicht vor dem & 227,0 & 223,1 & 228,6 & 225,2 & 0,3918 & \\
Experiment (g) & $\pm 8,3$ & $\pm 8,0$ & $\pm 10,4$ & $\pm 9,4$ & & \\
\hline Gewicht nach dem & 302,4 & 298,3 & 371,1 & 335,5 & $\mathbf{\leq 0 , 0 0 0 1}$ & 0,2525 \\
Experiment (g) & $\pm 20,9$ & $\pm 22,3$ & $\pm 40,8$ & $\pm 34,7$ & & \\
\hline Uterusgewicht (g) & 0,584 & 0,556 & 0,098 & 0,101 & $\leq \mathbf{0 , 0 0 0 1}$ & 0,6675 \\
& $\pm 0,153$ & $\pm 0,156$ & $\pm 0,019$ & $\pm 0,03$ & & \\
\hline
\end{tabular}

\subsection{Ergebnisse der Serumanalyse}

Die Serumkonzentration der Alkalischen Phosphatase ergab einen signifikanten Unterschied zwischen SHAM- und OVX-Tieren. Die Ganzkörpervibration erzielte keinen signifikanten Unterschied im Vergleich zur Kontrollgruppe.

Die Serumkonzentration von Osteocalcin unterschied sich nicht signifikant zwischen den unterschiedlichen Gruppen (Sehmisch et al. 2009b, Stürmer et al. 2010).

Tabelle 8: Ergebnisse der Serumanalyse (Angabe in MW \pm SD)

\begin{tabular}{|l|c|c|c|c|c|c|}
\hline Parameter & SHAM & SHAM Vib. & OVX & OVX Vib. & $\begin{array}{l}\text { OVX vs. } \\
\text { Sham }\end{array}$ & $\begin{array}{l}\text { Vib. vs. } \\
\text { nicht } \\
\text { Vib. }\end{array}$ \\
\hline Alkalische & 52 & 47 & 63 & 64 & $\leq 0,05$ & $>0,05$ \\
Phosphatase & \pm 5 & \pm 3 & \pm 4 & \pm 5 & & \\
$(\mathrm{U} / \mathrm{L})$ & & & & & & \\
\hline Osteocalcin & 22 & 19 & 21 & 27 & $>0,05$ & $>0,05$ \\
$(\mu \mathrm{g} / \mathrm{L})$ & \pm 2 & \pm 2 & \pm 2 & \pm 4 & & \\
\hline
\end{tabular}




\subsection{Ergebnisse der Mikroradiographie}

In der histomorphologischen Untersuchung zeigten die SHAM-Ratten in allen gemessenen Parametern signifikant bessere Ergebnisse verglichen zu den OVX-Ratten. Ganzkörpervibration induzierte eine signifikante Verbesserung in allen getesteten morphologischen Parametern. Siehe folgende Abschnitte (3.3.1-3.3.6).

\subsubsection{Kortikale Knochenflächendichte}

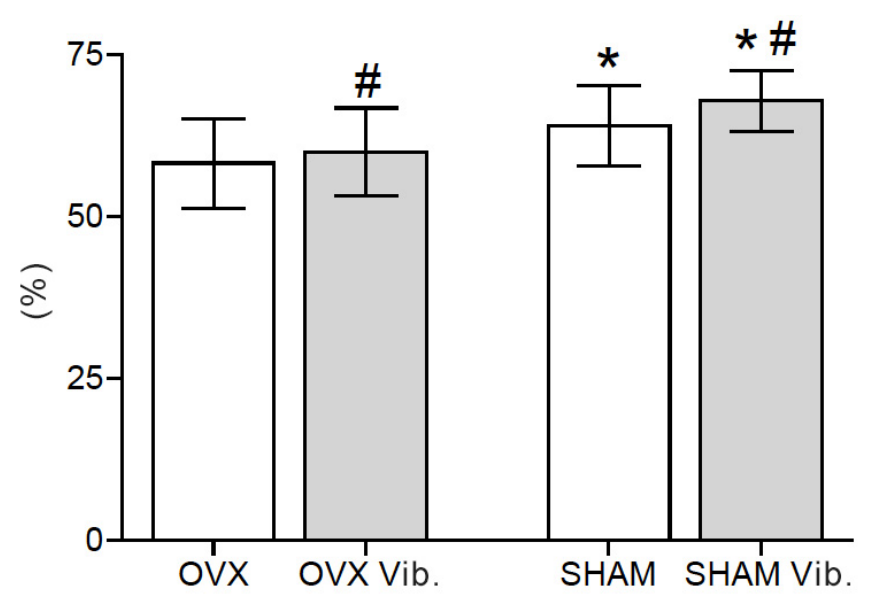

Abbildung 14: Kortikale Knochenflächendichte (\%)

( ${ }^{*} p \leq 0,05$ vs. OVX; $\# p \leq 0,05$ vs. nicht Vib.)

Die kortikale Knochenflächendichte der SHAM-Tiere ist signifikant erhöht zum Vergleich der OVX-Tiere. Das Vibrationstraining erzielte eine signifikante Verbesserung des Parameters. 


\subsubsection{Dichte Trabekelkreuzungen}

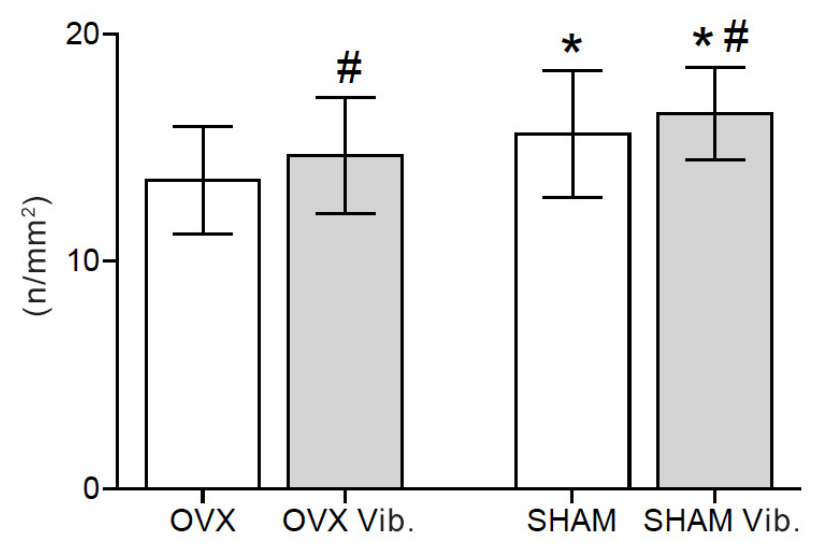

Abbildung 15: Dichte Trabekelkreuzungen $\left(\mathrm{n} / \mathrm{mm}^{2}\right)$

( ${ }^{*} p \leq 0,05$ vs. OVX; $\# p \leq 0,05$ vs. nicht Vib.)

Die Dichte der Trabekelkreuzungen in den SHAM-Tieren ist signifikant höher als in den OVX-Tieren. Das Vibrationstraining induzierte eine signifikante Verbesserung des gemessenen Wertes.

\subsubsection{Anzahl Trabekelkreuzungen absolut}

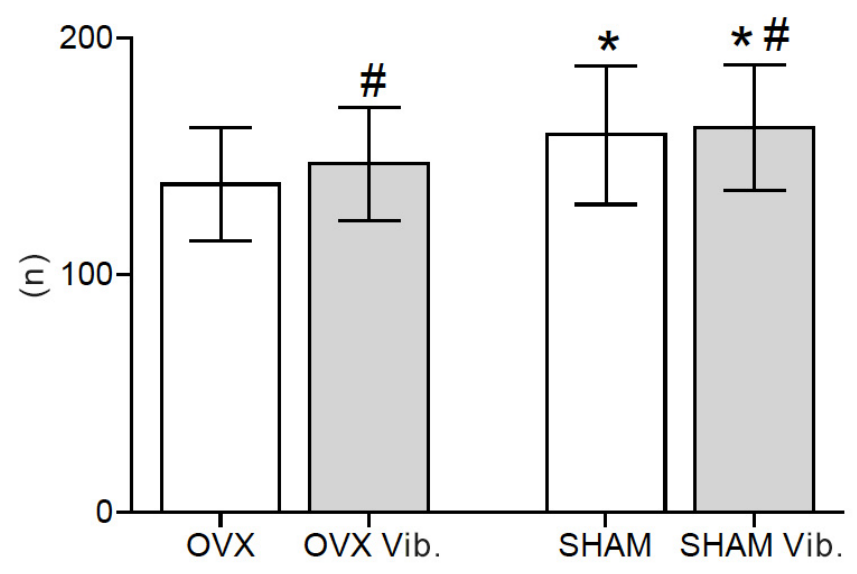

Abbildung 16: Anzahl der Trabekelkreuzungen absolut ( $n$ ) ( ${ }^{*} p \leq 0,05$ vs. OVX; \#p $\leq 0,05$ vs. nicht Vib.)

Die Anzahl der Trabekelkreuzungen ist signifikant erhöht in den SHAM-Tieren zum Vergleich der OVX-Tieren. Es zeigte sich eine signifikante Verbesserung des Parameters durch Vibrationstraining. 


\subsubsection{Trabekuläre Knochenfläche}

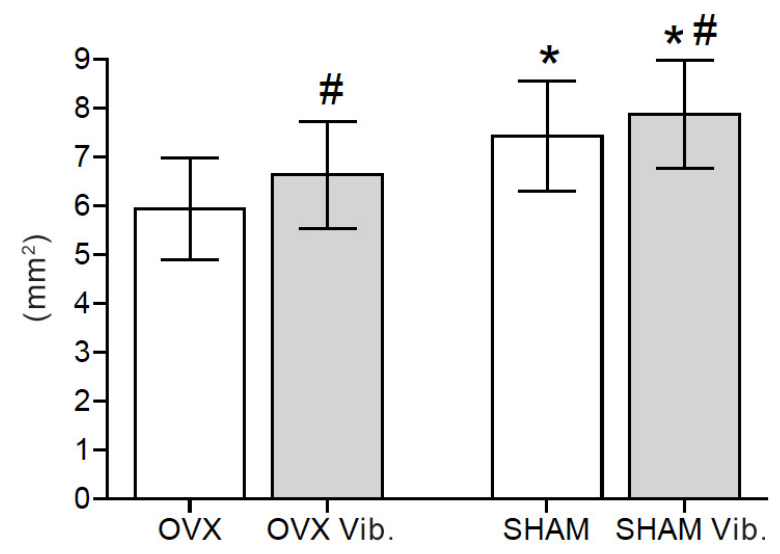

Abbildung 17: Trabekuläre Knochenfläche $\left(\mathrm{mm}^{2}\right)$

( ${ }^{*} p \leq 0,05$ vs. OVX; \#p $\leq 0,05$ vs. nicht Vib.)

Die trabekuläre Knochenfläche ist signifikant größer in den SHAM-Tieren zum Vergleich der OVX-Tieren. Auch hier erzielte die Ganzkörpervibration eine signifikante Verbesserung im untersuchten Parameter.

\subsubsection{Mittlere Trabekeldicke}

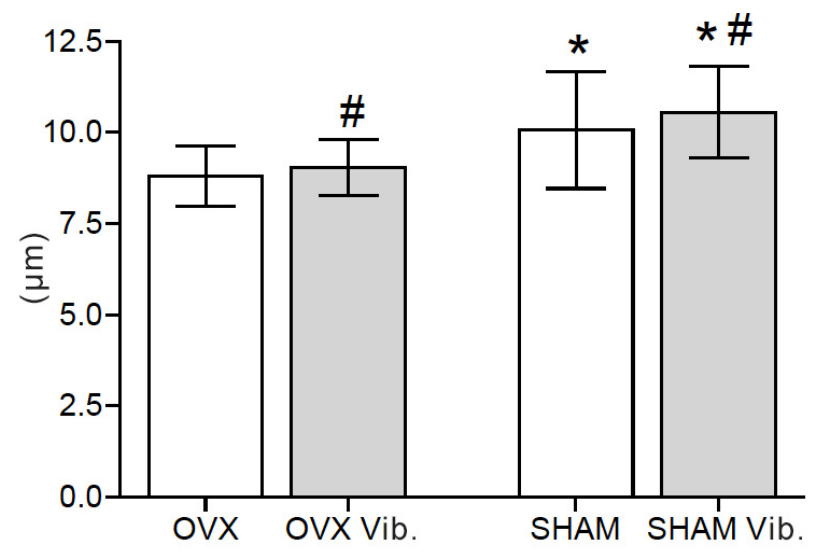

Abbildung 18: Mittlere Trabekeldicke ( $\mu \mathrm{m})$ ( ${ }^{*} p \leq 0,05$ vs. OVX; \#p $\leq 0,05$ vs. nicht Vib.)

Die mittlere Trabekeldicke zeigt eine signifikante Erhöhung in den SHAMTieren zum Vergleich zu den OVX-Tieren. Das Vibrationstraining erreichte eine signifikante Verbesserung im untersuchten Parameter. 


\subsubsection{Zusammenfassung der Ergebnisse der Mikroradiographie}

Die folgende Tabelle fasst die Ergebnisse der Mikroradiographie, wie in 3.3 beschrieben, zusammen.

Tabelle 9: Zusammenfassung der Ergebnisse der Mikroradiographie (Angabe in $M W_{ \pm} S D$ und $p$-Werte)

\begin{tabular}{|c|c|c|c|c|c|c|}
\hline Parameter & SHAM & SHAM Vib. & OVX & OVX Vib. & $\begin{array}{l}\text { OVX vs. } \\
\text { SHAM }\end{array}$ & $\begin{array}{l}\text { Vib. vs. } \\
\text { nicht } \\
\text { Vib. }\end{array}$ \\
\hline $\begin{array}{l}\text { Kortikale } \\
\text { Knochenflächen- } \\
\text { dichte (\%) }\end{array}$ & $\begin{array}{r}64,02 \\
\pm 6,20\end{array}$ & $\begin{array}{r}67,84 \\
\pm 4,68\end{array}$ & $\begin{array}{l}58,19 \\
\pm 6,92\end{array}$ & $\begin{array}{r}59,94 \\
\pm 6,79\end{array}$ & $\leq 0,0001$ & 0,0032 \\
\hline $\begin{array}{l}\text { Dichte } \\
\text { Trabekelkreuzun- } \\
\text { gen }\left(1 / \mathrm{mm}^{2}\right)\end{array}$ & $\begin{array}{r}15,59 \\
\pm 2,79\end{array}$ & $\begin{array}{r}16,49 \\
\pm 2,02\end{array}$ & $\begin{array}{r}13,55 \\
\pm 2,36\end{array}$ & $\begin{array}{r}14,65 \\
\pm 2,55\end{array}$ & $\leq 0,0001$ & 0,0086 \\
\hline $\begin{array}{l}\text { Anzahl } \\
\text { Trabekelkreuzun- } \\
\text { gen }(n)\end{array}$ & $\begin{array}{c}159 \\
\pm 29,2\end{array}$ & $\begin{array}{r}162 \\
\pm 26,5\end{array}$ & $\begin{array}{c}138 \\
\pm 23,8\end{array}$ & $\begin{array}{r}147 \\
\pm 23,8\end{array}$ & $\leq 0,0001$ & 0,0028 \\
\hline $\begin{array}{l}\text { Trabekuläre } \\
\text { Knochenfläche } \\
\left(\mathrm{mm}^{2}\right)\end{array}$ & $\begin{array}{r}7,42 \\
\pm 1,13\end{array}$ & $\begin{array}{r}7,87 \\
\pm 1,10\end{array}$ & $\begin{array}{r}5,94 \\
\pm 1,04\end{array}$ & $\begin{array}{r}6,63 \\
\pm 1,09\end{array}$ & $\leq 0,0001$ & 0,0006 \\
\hline $\begin{array}{l}\text { Mittlere } \\
\text { Trabekeldicke } \\
(\mu \mathrm{m})\end{array}$ & $\begin{array}{r}10,06 \\
\pm 1,60\end{array}$ & $\begin{array}{r}10,59 \\
\pm 1,25\end{array}$ & $\begin{array}{r}8,79 \\
\pm 0,82\end{array}$ & $\begin{array}{r}9,04 \\
\pm 0,78\end{array}$ & $\leq 0,0001$ & 0,0317 \\
\hline
\end{tabular}




\subsection{Ergebnisse des biomechanischen Kompressionstests}

\subsubsection{Maximalkraft}

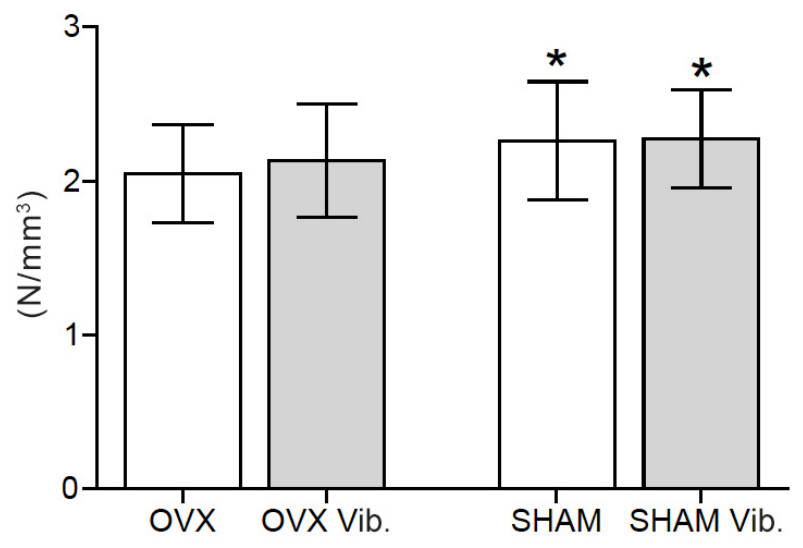

Abbildung 20: Maximalkraft in Bezug auf das Wirbelkörpervolumen ( $\left.\mathrm{N} / \mathrm{mm}^{3}\right)$ ( ${ }^{*} p \leq 0,05$ vs. OVX; \#p $\leq 0,05$ vs. nicht Vib.)

Die Maximalkraft der SHAM-Tiere ist signifikant erhöht im Vergleich zu den OVX-Tieren. Das Vibrationstraining konnte in diesem Messparameter keinen signifikanten Effekt erzielen.

\subsubsection{Yield Load}

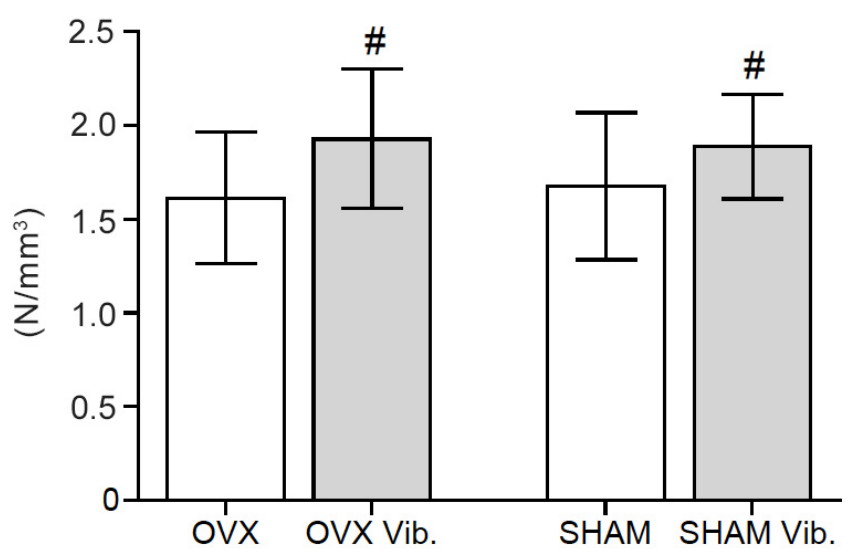

Abbildung 21: Yield Load in Bezug auf das Wirbelkörpervolumen $\left(\mathrm{N} / \mathrm{mm}^{3}\right)$ ( ${ }^{*} p \leq 0,05$ vs. OVX; \#p $\leq 0,05$ vs. nicht Vib.)

In Bezug auf den Parameter Yield Load konnten keine signifikanten Unterschiede zwischen den Gruppen OVX-Ratten und SHAM-Ratten 
gemessen werden. Wogegen die Ganzkörpervibration zu einer signifikanten Verbesserung des Parameters führte.

\subsubsection{Steigung}

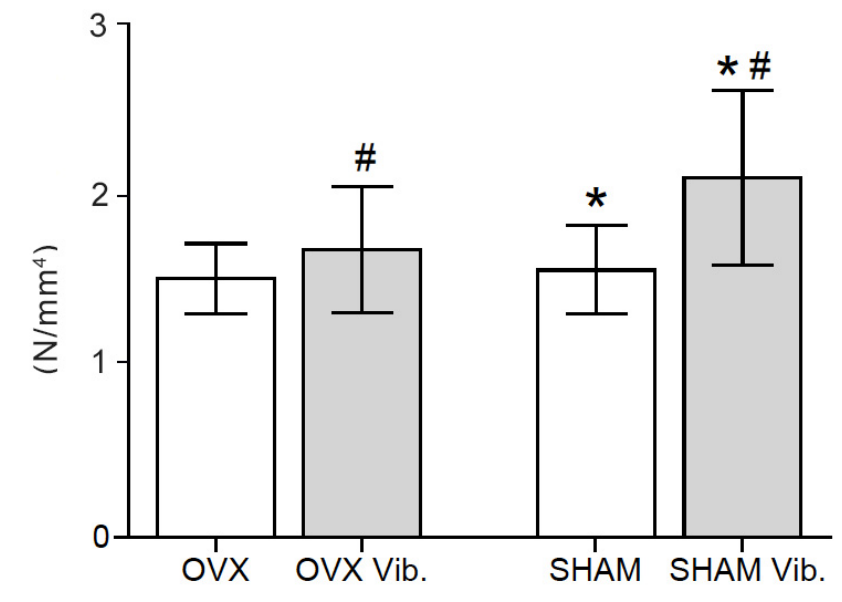

Abbildung 22: Steigung in Bezug auf das Wirbelkörpervolumen $\left(\mathrm{N} / \mathrm{mm}^{4}\right)$ ( ${ }^{*} p \leq 0,05$ vs. OVX; \#p $\leq 0,05$ vs. nicht Vib.)

Es finden sich in allen untersuchten Gruppen signifikante Unterschiede bezüglich der Steigung.

\subsubsection{Zusammenfassung der Ergebnisse des biomechanischen Kompressionstests}

Die folgende Tabelle fasst die Ergebnisse der biomechanischen Kompression zusammen.

Tabelle 10: Zusammenfassung der Ergebnisse des biomechanischen Kompressionstests (Angabe in $M W_{ \pm} S D$ und $p$-Werte)

\begin{tabular}{|c|c|c|c|c|c|c|}
\hline Parameter & SHAM & SHAM Vib. & OVX & OVX Vib. & $\begin{array}{l}\text { OVX vs. } \\
\text { SHAM }\end{array}$ & $\begin{array}{l}\text { Vib. vs. } \\
\text { nicht } \\
\text { Vib. }\end{array}$ \\
\hline $\begin{array}{l}\text { Maximalkraft/ } \\
\text { Volumen }\left(\mathrm{N} / \mathrm{mm}^{3}\right)\end{array}$ & $\begin{array}{r}2,467 \\
\pm 0,44\end{array}$ & $\begin{array}{r}2,521 \\
\pm 0,41\end{array}$ & $\begin{array}{l}2,113 \\
\pm 0,42\end{array}$ & $\begin{array}{r}2,22 \\
\pm 0,27\end{array}$ & 0,0043 & 0,1562 \\
\hline $\begin{array}{l}\text { Yield Load/ } \\
\text { Volumen }\left(\mathrm{N} / \mathrm{mm}^{3}\right)\end{array}$ & $\begin{array}{l}1,837 \\
\pm 0,5\end{array}$ & $\begin{array}{r}2,16 \\
\pm 0,33\end{array}$ & $\begin{array}{r}1,677 \\
\pm 0,32\end{array}$ & $\begin{array}{r}2,011 \\
\pm 0,34\end{array}$ & 0,1564 & 0,0036 \\
\hline $\begin{array}{l}\text { Steigung/ } \\
\text { Volumen }\left(\mathrm{N} / \mathrm{mm}^{4}\right)\end{array}$ & $\begin{array}{r}1,531 \\
\pm 0,35\end{array}$ & $\begin{array}{r}2,205 \\
\pm 0,58\end{array}$ & $\begin{array}{l}1,404 \\
\pm 0,23\end{array}$ & $\begin{array}{r}1,528 \\
\pm 0,38\end{array}$ & 0,0008 & 0,0009 \\
\hline
\end{tabular}




\subsection{Ergebnisse der Veraschung}

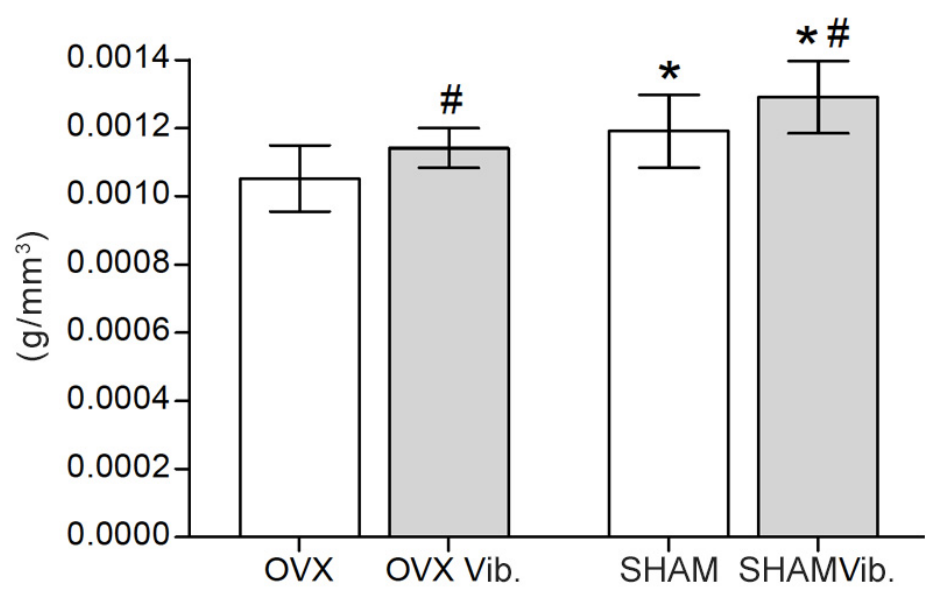

Abbildung 23: Knochenmineraldichte (=BMD) in Bezug auf das Wirbelkörpervolumen $\left(\mathrm{g} / \mathrm{mm}^{3}\right),\left({ }^{*} p \leq 0,05\right.$ vs. OVX; $\# p \leq 0,05$ vs. nicht Vib.)

Die Knochenmineraldichte der SHAM-Tiere war signifikant erhöht im Vergleich zu den OVX-Tieren. Das Vibrationstraining führte zu einer signifikanten Verbesserung der mineralischen Knochendichte in allen Gruppen.

Tabelle 11: Ergebnisse der Knochenmineraldichte-Messung (Angabe in $M W \pm S D$ und $p$-Werte)

\begin{tabular}{|l|c|c|c|c|l|l|}
\hline Parameter & SHAM & SHAM Vib. & OVX & OVX Vib. & $\begin{array}{l}\text { OVX vs. } \\
\text { SHAM }\end{array}$ & $\begin{array}{l}\text { Vib. vs. } \\
\text { nicht } \\
\text { Vib. }\end{array}$ \\
\hline BMD $\left(\mathrm{mg} / \mathrm{cm}^{3}\right)$ & 1,191 & 1,291 & 1,052 & 1,141 & $\leq \mathbf{0 0 0 1}$ & $\leq \mathbf{0 , 0 0 1 1}$ \\
& \pm 107 & \pm 106 & \pm 97 & \pm 59 & \\
\hline
\end{tabular}




\section{Diskussion}

\subsection{Die ovarektomierte Ratte als Tiermodell der Osteoporose}

Das in diesem Versuch verwendete Tiermodell ist die ovarektomierte Ratte. Diese stellt ein etabliertes und das am meisten verwendete Tiermodell in der postmenopausalen Osteoporoseforschung dar. Die durch die Ovariektomie induzierte Veränderung im Knochenstoffwechsel der Ratte gleicht in vielen Punkten den Folgen des Knochenverlustes der postmenopausalen Frau.

So führt Östrogenmangel bei Ratten zu einer gesteigerten Knochenresorption und zu einem fortschreitenden Verlust der Knochenmasse (Frost und Jee 1992, Wronski et al. 1991). Hierbei betrifft der Knochenabbau weitgehend den spongiösen Anteil der Knochenstruktur. Ikeda et al. zeigten eine signifikante Abnahme der Trabekeldicke im Lendenwirbelkörper bereits 42 Tage nach Ovarektomie (Ikeda et al. 2001). Dies ist auf eine gesteigerte Osteoklastenaktivität im trabekulärem Knochen zurückzuführen (Verhas et al. 1986). Ein weiterer Aspekt zur Vergleichbarkeit des Tiermodells mit dem Menschen ist das Ansprechen auf therapeutische Maßnahmen. Neben anderen Autoren bewiesen Wronski et al., dass insbesondere Östrogene knochenprotektiv auf die osteoporotische Ratte wirken können (Wronski et al. 1989).

Eine Einschränkung für das Tiermodell Ratte besteht in der klinischen Bedeutung der Erkrankung. Ovarektomierte Ratten entwickeln eine deutliche Osteopenie, die jedoch nicht automatisch zu einer Beeinträchtigung des Bewegungsapparates führt. Spontanfrakturen und Mikroläsionen konnten bisher nicht evaluiert werden (Jee und Yao 2001). Eine große Anzahl von verschiedenen Tierarten, einschließlich Nagetieren, Hasen, Hunden und Primaten wurden als Tiermodell für die Osteoporose verwendet. Aufgrund des Zugriffs auf ein ausgedehntes Detailwissen über das Knochengerüst und ein dem Menschen ähnelnden östrogendefizienten Knochenmetabolismus 
bevorzugen die meisten Forscher das Tiermodell Ratte in der Osteoporoseforschung (Lelovas et al. 2008).

\subsection{Analyse der Ergebnisse der Mikroradiographie}

Die Mikroradiographie ist zur Untersuchung der histomorphologischen Knochenqualität eine vielfach angewandte Methode. Sie ermöglicht die Darstellung der komplexen Knochenstruktur aus trabekulärem Netzwerk und kortikalem Rahmen im zweidimensionalen Bild. Mit Hilfe dieser Technik können Rückschlüsse über die Wirkung der Ganzkörpervibration auf die Knochenmorphologie gezogen werden.

In einer weiteren Studie mit ovarektomierten und intakten Ratten, die einer Ganzkörpervibration mit $45 \mathrm{~Hz}$ und $90 \mathrm{~Hz}, 28$ Tage lang unterzogen wurden, konnte ein positiver Effekt der WBV auf die Tibiae gezeigt werden. Die Auswertung der Histomorphologie ergab eine signifikante Zunahme des trabekulären Knochenvolumens um 12\% und der Trabekeldicke um 11\% bei den mit $90 \mathrm{~Hz}$ vibrierten Tieren im Vergleich zu den anderen Gruppen (Judex et al. 2007). Analog zu dieser Studie erzielte ein Vibrationsversuch an Femora von Schafen, die mit einer Frequenz von $30 \mathrm{~Hz}$ in einem Zeitraum von einem Jahr vibriert wurden, eine Verbesserung des trabekulären Knochenvolumens um 32\% und der Trabekelanzahl um 45\% im Vergleich zu den nicht vibrierten Kontrollgruppen (Rubin et al. 2002).

Trotz unterschiedlicher Ausgangsbedingungen der Versuche (Tiere, Knochen und Frequenzen) zeigen die Ergebnisse einen positiven Einfluss der WBV vor allem auf die trabekulären Bereiche des Knochens. Osteoanabole Effekte auf die kortikalen Knochenstrukturen hingegen sind bisher in der Literatur kontrovers diskutiert worden. Warden und Turner fanden heraus, dass Frequenzen größer als $10 \mathrm{~Hz}$ zu keinen Verbesserungen der kortikalen Knochenstruktur führen. Die Transduktion eines mechanischen Reizes in eine biologische Antwort scheint weniger effizient bei höheren Frequenzen zu sein (Warden und Turner 2004).

Diese Ergebnisse decken sich mit der Hypothese von Rubin et al., welche besagt, dass niedrigamplitudige und hochfrequente mechanische Stimulation 
anabol im trabekulären, jedoch nicht im kortikalen Knochen ist (Rubin et al. 2002). Im Kontrast hierzu stehen die Ergebnisse von Rubinacci et al., die eine Verbesserung der Knochenqualität des kortikalen Knochens bei einer Vibration von $30 \mathrm{~Hz}$ verifizieren konnte. Diese Arbeitsgruppe fand heraus, dass Ovarektomie das Ansprechen von Vibration vor allem auf den kortikalen Knochen erhöht. Des Weiteren ist der positive Effekt von der Größe der Vibrationsamplitude abhängig (Rubinacci et al. 2008).

Ein dieser Studie folgender Vibrationsversuch erforschte im gleichen Arbeitskreis die Auswirkung der WBV am Lendenwirbelkörper ovarektomierter Ratten mit verschiedenen Frequenzen. Hierbei zeigte sich eine Verbesserung der trabekulären Strukturen vor allem bei einer Frequenzzahl von $35 \mathrm{~Hz}$, wohingegen ein eher negativer Effekt bei der Vibration mit $90 \mathrm{~Hz} z u$ beobachten war. Eine Auswirkung auf die kortikale Struktur ergab sich nicht (Döll 2010). Es ist zu erwähnen, dass in dieser Studie nur einmal pro Tag die Tiere vibriert wurden, im Gegensatz zum präsentierten Versuch, in dem die Tiere zweimal am Tag einer WBV unterzogen wurden.

In der hier vorliegenden Studie induzierte Ganzkörpervibration eine signifikante Verbesserung in allen mikroradiographisch gemessenen Parametern. Gleichermaßen demonstrierten die SHAM-Ratten eine signifikante Verbesserung der Knochenmorphologie sowohl in den kortikalen als auch in den trabekulären Strukturen gegenüber den OVX-Ratten. Im Gegensatz zu erwähnten Studien erhöhte sich neben den trabekulären Messparametern auch die kortikale Knochenflächendichte der vibrierten Tiere signifikant zu den nicht vibrierten Tieren. Möglicherweise ist die Kombination einer höheren Vibrationsrate (zweimal täglich) mit einer hohen Frequenz (90 $\mathrm{Hz}$ ) besonders wirkungsvoll auf die Knochenmorphologie. Bei der Betrachtung der Messung des trabekulären Netzwerkes erhärtete sich diese Annahme. Sowohl die absolute als auch die relative Anzahl der Trabekelkreuzungspunkte war signifikant erhöht in allen Gruppen. Des Weiteren führte die WBV zur signifikanten Erweiterung der trabekulären Knochenfläche und signifikanten Zunahme der Trabekeldicke in allen vier Gruppen. 
Das Resultat der mikroradiographischen Auswertung konnte die Ergebnisse anderer Arbeitsgruppen unterstützen und um den Aspekt des osteoanabolen Effekts der WBV sowohl auf die trabekulären als auch auf die kortikalen Anteile des Lendenwirbelkörpers erweitern.

\subsection{Analyse der Ergebnisse des biomechanischen Kompressionstests}

Mit der biomechanischen Testung des Lendenwirbelkörpers wurde die mechanische Stabilität, mit Ermittlung der erreichbaren Maximalkraft und dem Auftreten erster trabekulärer Mikrofrakturen am osteoporotischen Knochen analysiert. Akhter et al. verifizierten, dass eine erhöhte BMD nicht unmittelbar mit einer verbesserten mechanischen Stabilität korreliert (Akhter et al. 2004). Ebenso werden Vermutungen gestellt, dass gute histomorphologische Ergebnisse nicht unbedingt mit einer verbesserten Stabilität des Knochens einhergehen (Stürmer et al. 2006). Demnach sind biomechanische Kompressionstests zur Vervollständigung der Untersuchung der Knochenqualität in der Osteoporoseforschung essentiell. Die Notwendigkeit der Analyse von trabekulären Mikrofrakturen am Achsentierskelett ist damit begründet, dass osteoporotische Frakturen hauptsächlich in den Lendenwirbelkörpern, in Form von Sinterungsfrakturen und in der Metaphyse der Tibia vorkommen (Chachra et al. 1995, Ikeda et al. 2001). In der Population der 50-79-jährigen Frauen und Männer beträgt die Inzidenz von Osteoporose-assoziierten Wirbelkörperfrakturen ca. 74000 pro Jahr in Europa (O'Neill et al. 1996). Des Weiteren sind Wirbelkörperfrakturen ein wichtiger Prognosefaktor für das Ausmaß und den Verlauf einer Osteoporose (Genant et al. 2007).

Bisher finden sich in der Literatur vor allem Daten über Kompressionstests an Tibiae und Femora (Flieger et al. 1998, Oxlund et al. 2003). Einige Studien zeigen auch Untersuchungen am Lendenwirbelkörper, diese wurden jedoch nur im vorpräparierten Zustand komprimiert, mit dem Ziel einer reproduzierbaren Untersuchung (lkeda et al. 2001, Breitman et al. 2005). Sehmisch et al. entwickelten ein Kompressionsverfahren, in dem der Wirbelkörper erstmalig im Ganzen untersucht wurde (Sehmisch et al. 2009a). 
Dieses wurde auch in der hier präsentierten Studie angewandt. Der klare Vorteil der Analyse der intakten Lendenwirbelkörper liegt in der Möglichkeit, sowohl die kortikale als auch die trabekuläre Knochenqualität zu messen. Wirbelkörper müssen als eine funktionale Einheit gesehen werde, deren mechanische Stabilität aus dem Zusammenspiel einer kortikalen Hülle und einem inneren trabekulärem Netzwerk resultiert.

In einem Vibrationsversuch mit ovarektomierten Ratten führte die mechanische Stimulation zu einer, wenn auch nicht signifikant erhöhten Stabilität der Femora (Flieger et al. 1998). Dies konnte in einem weiteren Tierversuch von Oxlund et al. bestätigt werde. Tägliche Vibration mit 17 und $45 \mathrm{~Hz}$ in einem Zeitraum von 90 Tagen führte zu einer höheren mechanischen Belastbarkeit der Femora und Tibiae ovarektomierter Ratten (Oxlund et al. 2003). Diesem Versuch folgende Studien, innerhalb unseres Arbeitskreises, ergaben ebenfalls einen höchsten Effekt auf die biomechanische Festigkeit bei niedrigen Vibrationsfrequenzen (Döll 2010, Fürst 2014).

Einige Autoren untersuchten den Zusammenhang der mechanischen Widerstandskraft mit dem Volumen des komprimierten Körpers. Je höher das Körpervolumen, desto höher scheint die biomechanische Stabilität zu sein (Ruyssen-Witrand et al. 2007). Basierend auf diesen Daten wurden die gemessenen Parameter Steigung, Yield Load und Maximalkraft in Relation zum jeweiligen Volumen des Wirbelkörpers gesetzt.

Wie zu erwarten, fand sich in den Ergebnissen der hier durchgeführten Untersuchung im Vergleich zu den osteoporotischen Ratten, eine signifikant höhere biomechanische Festigkeit bei den intakten Tieren. Sowohl die elastische Verformung (Steigung) als auch der Widerstand des Knochens (Maximalkraft) waren bei den gesunden Tieren signifikant erhöht.

Das Vibrationstraining konnte die elastische Verformung des Knochens signifikant verbessern. Bei der Analyse der zu erreichenden Maximalkraft war der Vibrationseffekt geringer ausgeprägt.

Die ersten Mikrofrakturen des trabekulären Knochenmaterials, die als Übergang der elastischen zur plastischen Verformung des Knochens (Yield Load) präsentiert wurden, traten nach Vibrationstraining signifikant später auf. 
Insbesondere diese Verzögerung von trabekulären Mikrofrakturen kann zu einem klinisch bedeutenden Effekt führen. Beim Menschen führen Standardbelastungen zu trabekulären Mikrofrakturen, die nach Überschreitung einer kritischen Anzahl zur definitiven Fraktur führen (Dendorfer et al. 2009). Durch ein gezieltes Aufbautraining der Trabekel könnten manifeste Frakturen verringert werden.

Zusammenfassend decken sich die Ergebnisse dieser Arbeit mit dem Beweis der Verbesserung mechanischer Festigkeit des osteoporotischen Knochens durch WBV mit den bisher veröffentlichten Daten.

\subsection{Analyse der Ergebnisse der Veraschung}

Durch Veraschung der Wirbelkörper konnte die Knochenmineraldichte (BMD) berechnet und daraufhin die Auswirkung der WBV auf den mineralischen Gehalt der Knochen analysiert werden. Die Knochendichtemessung ist eine wichtige Maßnahme zur Überprüfung der WHO-Definition einer Osteoporose und zur Erfassung des Ausmaßes der Knochendichteerniedrigung, die wiederum mit dem individuellen Frakturrisiko korreliert (DVO 2009).

Die positive Wirkung der WBV auf die BMD konnte sowohl anhand von Tierversuchen als auch in anschließenden klinischen Studien belegt werden. Flieger et al. betrachteten erstmal 1998 den Einfluss der WBV am Tiermodell. Sie fanden heraus, dass Vibrationstraining zu einer Verringerung des postmenopausalen Knochensubstanzverlustes führen kann. Nach WBV mit $50 \mathrm{~Hz}$ für 30 Minuten über einem Zeitraum von drei Monaten ergab sich eine signifikant höhere Knochendichte in den Tibiae und Femora der vibrierten Tiere, als bei den nicht vibrierten Tieren. Eine randomisierte Doppelblindstudie mit 70 Frauen nach der Menopause, erwies eine Hemmung der postmenopausalen BMD-Abnahme an der Wirbelsäule. Die Hälfte der Probandinnen mussten ein Jahr lang täglich zehn Minuten auf einer mit $30 \mathrm{~Hz}$ vibrierten Plattform stehen, wobei der anderen Hälfte keiner WBV unterzogen wurde. Mittels DXA wurde die Knochendichte zu Beginn, nach sechs und nach zwölf Monaten gemessen. Während die Kontrollgruppe einen Verlust der Knochendichte in der Wirbelsäule von 1,6\% verzeichnen 
musste, zeigte sich in der vibrierten Gruppe nur ein Verlust der BMD von $0,1 \%$, was einem relativen Gewinn von 1,5\% entspricht (Rubin et al. 2004). Eine weitere klinische Studie von Verschueren et al. beschreibt eine signifikante Zunahme der Knochendichte im Bereich des proximalen Femurs postmenopausaler Frauen (Verschueren et al. 2004). Im Kontrast dazu steht eine klinische Studie mit 56 jungen Erwachsenen. In dieser konnte ein vierminütiges Vibrationsprogramm für acht Monate mit maximal $45 \mathrm{~Hz}$ keine Verbesserung der Knochendichte erzielen (Torvinen et al. 2003). Ein möglicher Grund für das negative Ergebnis könnte die kurze Dauer der Vibrationsbehandlung sein. Eine Metaanalyse über den Effekt WBV auf die Knochendichte bestätigte die positiven Ergebnisse. Eingeschlossen wurden acht randomisierte, kontrollierte Studien, welche eine signifikante Verbesserung der BMD der Hüfte postmenopausaler Frauen, der Tibia und der Wirbelsäule junger Erwachsener beweisen konnten (Slatkovska et al. 2010).

Bei der Bestimmung der Knochenmineraldichte der hier untersuchten Tiere, zeigten sich signifikante Unterschiede zwischen den OVX- und den SHAMoperierten Tieren. Die SHAM-operierten Ratten hatten nach Veraschung eine höhere Knochenmineraldichte als die OVX-Tiere. Das Vibrationstraining bewirkte sowohl bei den OVX- als auch bei den SHAM-Tieren eine signifikante Erhöhung der Messwerte im Vergleich zu den Kontrollgruppen.

WBV scheint nach diesen Ergebnissen einen positiven Effekt auf die Knochenmineraldichte $\mathrm{zu}$ haben. Insgesamt hat sich die Knochenmineraldichte durch WBV in allen Gruppen verbessert, wobei die Werte der OVX-Tiere immer unter denen, der SHAM-Tiere lagen. Die Ergebnisse des vorliegenden Experimentes bestätigen die Untersuchung anderer Arbeitsgruppen und somit die positive Wirkung von Vibration auf die Knochendichte. 


\subsection{Deutung und kritische Betrachtung der Versuche}

Die vorliegenden Ergebnisse konnten belegen, dass mechanische Stimulation unter den hier ausgesuchten Vibrationsbedingungen den Lendenwirbelkörper der Ratte positiv beeinflusst. Die Auswertungen beziehen sich auf eine ganz bestimmte Technik der mechanischen Stimulation. Die Entscheidung, niedrigamplitudige und hochfrequente Stimulation zu nutzen, beruhte auf positive Ergebnisse anderer Studien, in denen hohe Frequenzen angewandt wurden (Judex et al. 2007). Eine Einschränkung dieser Arbeit ist, dass nur eine Frequenz, eine Amplitude und eine Richtung der Vibration (vertikal) verwendet wurden und nicht mit unterschiedlichen Vibrationsarten verglichen wurde. Im Hinblick auf die derzeitigen Daten der Osteoporoseforschung bleibt weiterhin die Frage offen, welche die effektivste Frequenz, Amplitude, Dauer und Wiederholungssequenz der Vibration sein mag. Weiterhin lässt sich die positive Wirkung der WBV nicht auf andere Knochenareale, auf männliche Tiere und nicht einfach auf den Menschen übertragen.

Ein weiterer zu diskutierender Aspekt ist die Wirkung der mechanischen Stimulation auf die unterschiedlich eingenommenen Körperpositionen. Es gibt klinische Studien, in denen die Probandinnen während der Vibration verschiedene physikalische Übungen machen mussten (Verschueren et al. 2004, Torvinen et al. 2003). Tierexperimentelle Vibrationstests an Schafen benutzen eher eine fixierte Ausgangsposition (Rubin et al. 2002). In dieser Studie durften die Ratten während der Vibration frei herumlaufen. Sie stellten sich teilweise auf die Hinterbeine. Dies könnte zu einer stärkeren axialen Stimulation geführt haben. Es ist jedoch auch möglich, dass die Elastizität des Muskel-Bandapparates die Stimulation bei Veränderungen der Körperposition, dämpfen könnte (Castillo et al. 2006). Es ist in Betracht zu ziehen, dass der Effekt der mechanischen Stimulation von der jeweiligen Körperposition auf der Vibrationsplattform abhängen könnte. Die Osteoporoseforschung zeigt Studien mit den unterschiedlichsten Vibrationsbedingungen und Tiermodellen. Um eine bessere Vergleichbarkeit unter den Studien herzustellen ist zu erwägen, ähnliche Ausgangsbedingungen in zukünftigen Versuchen zu schaffen. 


\section{Zusammenfassung}

Die Behandlung und Prophylaxe der Osteoporose stellt eine der größten medizinischen Herausforderungen unserer Zeit dar. Körperliches Training ist ein wesentlicher Grundpfeiler bei der Behandlung dieser Erkrankung. Grundlage dafür ist die Tatsache, dass Knochen auf von außen einwirkende Kräfte reagieren können. In dieser Untersuchung wurde der Effekt von vertikaler Ganzkörpervibration (WBVV) in Form von niedrigamplitudiger, hochfrequenter mechanischer Stimulation am Osteoporose-Rattenmodell getestet.

Für die Studie wurden 60 weibliche Ratten untersucht. Im Alter von drei Monaten wurde die Hälfte der Tiere ovarektomiert (OVX) und die andere Hälfte SHAM-operiert, um als gesunde Kontrollgruppe zu fungieren (SHAM). Die ovarektomierten Ratten entwickelten in den folgenden zwölf Wochen Osteoporose. Nach zehn Wochen und fünf Tagen wurde mit der mechanischen Stimulation mittels vertikaler Ganzkörpervibration begonnen. Für den Vibrationsversuch wurde von beiden Gruppen, SHAM und OVX, jeweils die Hälfte der Ratten verwendet (SHAM Vib., OVX Vib.). Über einen Zeitraum von 30 Tage wurden die Tiere zweimal täglich 15 Minuten mit einer Frequenz von $90 \mathrm{~Hz}$ vibriert.

Nach Tötung der Tiere wurden verschiedene Lendenwirbelkörper präpariert und zur Analyse der Vibrationseffekte den einzelnen Untersuchungen zugeführt. Am I. LWK wurde die morphologische Eigenschaft des Knochens mittels Mikroradiographie untersucht. Zur Testung der mechanischen Belastbarkeit wurde der IV. LWK einem standardisierten biomechanischen Kompressionstest unterzogen. Abschließend erfolgte die Berechnung der mineralischen Knochendichte (BMD) am II. LWK nach dessen Veraschung.

Die Auswertung der Ergebnisse zeigte einen überwiegend positiven Einfluss der Ganzkörpervibration auf morphologische Parameter, Stabilität und Knochenmineraldichte der osteoporotischen und intakten Lendenwirbelkörper. Die Ergebnisse der Mikroradiographie ergaben in allen gemessenen Parametern eine signifikante Verbesserung der morpho- 
logischen Struktur des Knochens. Hierbei zeigte die Behandlung mit WBV einen größeren Effekt auf den trabekulären Knochen als auf den kortikalen Knochen.

In der Messung der biomechanischen Festigkeit konnte durch WBV eine signifikante Verbesserung der Yield Load gezeigt werden. So traten die ersten Mikrofrakturen des trabekulären Knochenmaterials, die als Übergang der elastischen zur plastischen Verformung des Knochens (Yield Load) präsentiert wurden, signifikant später auf. Bezüglich der Yield Load und der Steigung entsprechend der elastischen Verformung des Knochens erreichten die behandelten ovarektomierten Tiere den Level der unbehandelten SHAMTiere. Bei der Analyse der Widerstandskraft des Knochens (Maximalkraft) war der Vibrationseffekt geringer ausgeprägt. Die Knochenmineraldichtemessung wiederum bestätigte den positiven Effekt der WBV mit erhöhten Messwerten bei den behandelten ovarektomierten und intakten Tieren.

Die Ergebnisse dieser Untersuchungen zeigen, dass niedrigamplitudige, hochfrequente Ganzkörpervibration eine sehr gute Ergänzung zu bereits etablierten Anti-Osteoporosetherapien darstellen könnte. Es sind dennoch weitere Untersuchungen erforderlich, die diesen neuen Therapieansatz und mögliche Nebenwirkungen analysieren. 


\section{Literaturverzeichnis}

Akhter MP, Otero JK, Iwaniec UT, Cullen DM, Haynatzki GR, Recker RR (2004): Differences in vertebral structure and strength of inbred female mouse strains. J Musculoskelet Neuronal Interact $\underline{4}$, 33-40

Aleyaasin M, Harrigan JJ (2008): Vibration exercise for treatment of osteoporosis: A theoretical model. Proc Inst Mech Eng H 222 (7), 1161-6

Bahlous A, Kalail E, Hadj Salah M, Bouzid K, Zerelli L (2006): Biochemical markers of bone remodelling: Recent data of their applications in managing postmenopausal osteoporosis. Tunis Med 84 (11), 751-7

Bartl R: Osteoporose-Prävention, Diagnostik, Therapie. 3. Auflage; ThiemeVerlag, Stuttgart 2008

Boskey AL, Di Carlo E, Paschalis E, West P, Mendelsohn R (2005): Comparison of mineral quality and quantity in iliac crest biopsies from highand low-turnover osteoporosis: an FT-IR microspectroscopic investigation Osteoporos Int 16, 2031-2038

Breitman PL, Fonseca D, Ward WE (2005): Combination of soy protein and high dietary calcium on bone biomechanics and bone mineral density in ovariectomized 86 rats. Menopause $\underline{12}$ (4), 428-435

Budsberg SC, Jevens DJ, Brown J, Foutz TL, De Camp CE, Reece L (1993): Evaluation of limb symmetry indices, using ground reaction forces in healthy dogs. Am J Vet Res 54, 1569-1574

Burger EH, Klein-Nulend J (1999): Mechanotransduction in bone - role of the lacunocanalicular network. FASEB J $\underline{13}, 101-112$

Canalis E, Giustina A Bilezikian JP (2007): Mechanisms of anabolic therapies for osteoporosis. N Engl J Med 357 (9), 905-916

Castillo AB, Alam I, Tanaka SM, Levenda J, Li J, Warden SJ, Turner CH (2006): Low-amplitude, broad-frequency vibration effects on cortical bone formation in mice. Bone $\underline{39}$, 1087-1096 
Chachra D, Kasra M, Vanin CM, Mac Lusky NJ, Casper RF, Grynpas MD (1995): The effect of different hormone replacement therapy regimes on the mechanical properties of rat vertebra. Calcif Tissue Int $\underline{56}, 130-134$

Chan ME, Gunes U, Rubin CT (2013): The potential benefits and inherent risks of vibration as a non-drug therapy for the prevention and treatment of osteoporosis. Curr Osteoporos 11, 36-44

Classen M, Diehl V, Kochsiek K: Innere Medizin. 5. Auflage; Urban \& Fischer in Elsevier, München 2004

Consensus Development Conference (1993): Diagnosis, prophylaxis and treatment of osteoporosis. Am J Med 94 (6), 646-650

Cooper C (1999): Epidemiology of osteoporosis. Osteoporos Int $\underline{9}$ (2), 2-8

Cranney A, Tugwell P, Zytaruk N, Robinson V, Weaver B, Adachi J, Wells G, Shea B, Guyatt G, Osteoporosis Methodology Group et al. (2002): Metaanalyses of therapies for postmenopausal osteoporosis. IV. Meta-analysis of raloxifene for the prevention and treatment of postmenopausal osteoporosis. Endocr Rev 23 (4), 524-8

Cummings SR, Bates D, Black DM (2002): Clinical use of bone densitometry: Scientific review JAMA 288, 1889-1897

Dalsky GP, Stocke KS, Ehsani AA, Slatopolsky E, Lee WC, Birge SJ (1988): Weight-bearing exercise training and lumbar bone mineral content in postmenopausal women. Ann Intern Med 1988 Jun 108 (6), 824-8

Delmas PD, Recker RR, Chesnut CH, Skag A, Stakkestad JA, Emkey R, Gilbride J, Schimmer RC, Christiansen C (2004): Daily and intermittent oral ibandronate normalize bone turnover and provide significant reduction in vertebral fracture risk: results from the BONE study. Osteoporos Int $\underline{15}$ (10), $792-8$

Dendorfer S, Maier HJ, Hammer J (2009): Fatigue damage in cancellous bone: an experimental approach from continuum to micro scale. $\mathrm{J}$ Mech Behav Bilmed Mater 2 (1), 113-119

Dietel M, Suttorp N, Zeitz M: Harrisons Innere Medizin. Band 2. 17. Auflage; ABW Wissenschaftsverlagsgesellschaft, Berlin 2009

Döll C: Einfluss der vertikalen Ganzkörpervibration unterschiedlicher Frequenzen auf den osteoporotischen Lendenwirbelkörper der Ratte. Med. Diss. Göttingen 2010 
DVO 2009: Prophylaxe, Diagnostik und Therapie der Osteoporose bei Erwachsene. Leitlinie des Dachverbands der Deutschsprachigen Wissenschaftlichen Osteologischen Gesellschaften e.V.

Eastell R, Hannon RA (2008): Biomarkers of bone health and osteoporosis risk. Proc Nutr Soc $\underline{67}$ (2), 157-62

Erren M: Biomechanischer Kompressionstest und Wirkung von Phytohormonen am corpus vertebrae der osteopenischen Ratte. Med. Diss. Göttingen 2007

Flieger J, Karachalios T, Khaldi L, Raptou P, Lyritis G (1998): Mechanical stimulation in the form of vibration prevents postmenopausal bone loss in ovariectomized rats. Calcif Tissue Int $\underline{63}$ (6), 510-4

Frost HM (1997): Defining Osteopenias and Osteoporoses: Another view (with insights from a new paradigm). Bone 20 (5), 385-391

Frost HM, Jee WSS (1992): On the rat model of human osteopenias an osteoporosis. Bone Miner 18, 227-236

Fürst B: Einfluss der vertikalen und horizontalen Ganzkörpervibration mit verschiedenen Frequenzen auf die Lendenwirbelsäule im Rattentiermodell. Med. Diss. Göttingen 2014

Garnero P (2008): Biomarkers for osteoporosis management: Utility in diagnosis, fracture risk prediction and therapy monitoring. Mol Diagn Ther $\underline{12}$ (3), 157-70

Genant HK, Delmas PD, Chen P, Jiang Y, Eriksen EF, Dalsky GP, Marcus R, San Martin J (2007): Severity of vertebral fracture reflects deterioration of bone microarchitecture. Osteoporos Int 18, 69-76

Gennari C (2001): Calcium and Vitamin D nutrition and bone disease of elderly women. Public Health Nutr 4 (2B), 547-59

Gilsanz V, Wren TA, Sanchez M, Dorey F, Judex S, Rubin C (2006): Lowlevel, high-frequency mechanical signals enhance musculoskeletal development of young women with low BMD. Bone 21 (9), 1464-74

Glüer CC, Barkmann R, Hahn HK, Majumdar S, Eckstein F, Nickelsen TN, Bolte H, Dicken V, Heller M (2006): Parametric biomedical imaging-what defines the quality of quantitative radiological approaches? Rofo $\underline{178}$ (12), $1187-201$ 
Hadji P (2005): Endogene und exogene Östrogene - Einfluss auf die Veränderungen des Knochenstoffwechsels in der Postmenopause. Gynäkologe $\underline{38}, 1065-1073$

Hadji P, Bock K, Wüster C (2001): Osteodensitometrie: Quo vadis? Möglichkeiten und Grenzen der modernen Osteoporosediagnostik. Reproduktionsmedizin 17, 261-270

Hadjiuargyrou M, Mcleod K, Ryaby JP, Rubin C (1998): Enhancement of fracture healing by low intensity ultrasound. Clin Orthop Relat Res $\underline{355}$, 216229

Harris ST, Watts NB, Genant HK, McKeever CD, Hangartner T, Keller M, Chesnut CH, Brown J, Eriksen EF, Hoseyni MS (1999): Effects of risedronate treatment on vertebral and nonvertebral fractures in women with postmenopausal osteoporosis: a randomized controlled trial. Vertebral Efficacy with Risedronate Therapy (VERT) Study Group. Jama 282, 13441352

Haussler B, Gothe H, Gol D, Glaeske G, Pientka L, Felsenberg D (2007): Epidemiology, treatment and costs of osteoporosis in German-the Bone EVA Study. Osteoporos Int 18 (1), 77-84

Hebel R, Stromberg MW: Anatomy and embryology of the laboratory rat. Biomed, Wörthsee 1986

Hughes DE, Dai A, Tiffee JC, Li HH, Mundy GR, Boyce BF (1996): Estrogen promotes apoptosis of murine osteoclasts mediated by TGF-beta. Nat Med $\underline{2}$ (10), $1132-6$

Ikeda S, Tsurukami $H$, Ito $M$, Sakai $A$, Sakata $T$, Nishida $S$, Takeda $S$, Shiraishi A, Nakamura T (2001): Effect of trabecular bone contour on ultimate strength of lumbar vertebra after bilateral ovariectomy in rats. Bone $\underline{28}, 625-$ 633

Ishihara A, Sasaki T, Debari K, Furuya R, Kawawa T, Ramamurthy NS, Golub LM (1999): Effects of ovariectomy on bone morphology in maxillae of mature rats. J Electron Microsc (Tokyo) $\underline{48}$, 465-569

Jee WS, Yao W (2001): Overview: animal models of osteopenia and osteoporosis. J Musculoskelet Neuronal Interact 1 (3), 193-207 
Judex S, Lei X, Han D, Rubin C (2007): Low-magnitude mechanical signals that stimulate bone formation in the ovariectomized rat are dependent on the applied frequency but not on the strain magnitude. J Biomech $\underline{40}$ (6), 1333-9

Judex S, Rubin CT (2010): Is bone formation induced by high-frequency mechanical signals modulated by muscle activity? J Musculoskelet Neuronal Interact 10, 3-11

Junqueira LC, Carneiro J: Histologie. Springer Medizin Verlag; Heidelberg 2005

Kalu DN (1991): The ovariectomized rat model of postmenopausal bon loss. Bone Miner 15, 175-192

Kemmler W, von Stengel S, Weineck J, Engelke K (2003): Empfehlungen für ein körperliches Training zur Verbesserung der Knochenfestigkeit: Schlussfolgerungen aus Tiermodellen und Untersuchungen an Leistungssportlern: Dtsch Z für Sportmed $\underline{54}$ (11), 306-316

Komrakova M, Stürmer EK, Tezval M, Stürmer KM, Dullin C, Schmelz U, Carolin Döll, Durkaya-Burchardt N, Fürst B, Genotte T et al. (2017): Evaluation of twelve vibration regimes applied to improve spine properties in ovariectomized rats. Bone Rep $\underline{7}, 172-180$

Lane NE (2006): Epidemiology, etiology, and diagnosis of osteoporosis. Am j Obstet Gynecol 194 (2), 3-11

Lau E, Al-Dujaili S, Guenther A, Liu D, Wang L, You L (2010): Effect of lowmagnitude, high-frequency vibration on osteocytes in the regulation of osteoclasts. Bone $\underline{46}$ (6), 1508-15

Lelovas PP, Xanthos TT, Thoma SE, Lyritis GP, Donatas IA (2008): The Laboratory Rat as an Animal Model for Osteoporosis Research. Comp Med $\underline{58}$ (5), 424-430

Lippert H: Lehrbuch Anatomie. 6. Auflage; Urban\&Fischer Verlag, München 2003

Lüllmann-Rauch: Taschenlehrbuch Histologie. 2. Auflage; Georg Thieme Verlag, Stuttgart 2006

Marie PJ (2005): Strontium ranelate: a novel mode of action optimizing bone formation and resorption. Osteoporos Int $\underline{16}$ (1), 7-10 
McClung MR, Geusens P, Miller PD, Zippel H, Bensen WG, Roux C, Adami S, Fogelman I, Diamond T, Eastell R (2001): Effect of risedronate on the risk of hip fracture in elderly women. Hip Intervention Program Study Group. N Engl J Med 344, 333-340

O'Neill TW, Felsenberg D, Varlow J, Cooper C, Kanis JA, Silmann AJ (1996): The prevalence of vertebral deformity in european men and women: The European Vertebral Osteoporosis Study. J Bone Miner Res 11, 1010-1018

Oxlund BS, Ortoft G, Andreassen TT Oxlund H (2003): Low-intensity, highfrequency vibration appears to prevent the decrease in strength of the femur and tibia associated with ovariectomy of adult rats. Bone $\underline{32}$ (1), 69-77

Pacifici R (1998): Cytokines, estrogen, and postmenopausal osteoporosis thesecond decade. Endocrinology 139 (6), 2659-2661

Parfitt AM, Drezner MK, Glorieux FH, Kanis JA, Malluche H, Meunier PJ, Ott SM, Recker RR (1987): Bone histomorphometry: standardization of nomenclature, symbols, and units. Report of the ASBMR Histomorphometry Nomenclature Committee. J Bone Miner Res 2, 595-610

Prisby RD, Lafage-Proust MH, Malaval L, Belli A, Vico L (2008): Effects of whole body vibration on the skeleton and other organ systems in man and animal models: what we know and what we need to know. Ageing Res Rev $\underline{7}$ (4), 319-29

Rauch $F$, Sievanen $H$, Boonen S, Cardinale M, Degens $H$, Felsenberg D, Roth J, Schoenau E, Verschueren S, Rittweger J (2010): Reporting wholebody vibration intervention studies: Recommendation of the International Society of Musculoskeletal and Neuronal Interactions. J Musculoskelet Neuronal Interact 10 (3), 193-198

Reginster J, Minne HW, Sorensen OH, Hooper M, Roux C, Brandi ML, Lund B, Ethgen D, Pack S, Roumagnac I et al. (2000): Randomized trial of the effects of risedronate on vertebral fractures in women with established postmenopausal osteoporosis. Vertebral Efficacy with Risedronate Therapy (VERT) Study Group. Osteoporos Int 11 (1), 83-91

Rodin A, Murby B, Smith MA, Caleffi M, Fentiman I, Chapman MG, Fogelman I (1990): Premenopausal bone loss in the lumbar spine and neck of femur: a study of 225 Caucasian women. Bone 11 (1), 1-5 
Rubin C, Recker R, Cullen D, Ryaby J, McCabe J, McLeod K (2004): Prevention of postmenopausal bone loss by a low-magnitude, high-frequency mechanical stimuli: a clinical trial assessing compliance, efficacy, and safety. J Bone Miner Res $\underline{19}$ (3), 343-51

Rubin C, Turner AS, Mallinckrodt C, Jerome C, McLeod K, Bain S (2002): Mechanical strain, induced noninvasively in the high-frequency domain, is anabolic to cancellous bone, but not cortical bone. Bone $\underline{30}$ (3), 445-452

Rubin CT, Judex S, Qin Yi (2006): Low-level mechanical Signals and their potential as a non-pharmacological intervention for osteoporosis. Age Ageing $\underline{35}$ (2), 32-36

Rubin CT, Sommerfeldt DW, Judex S, Qin Y (2001): Inhibition of osteopenia by low magnitude, high-frequency mechanical stimuli. Drug Discov Today $\underline{6}$ (16), 848-858

Rubinacci A, Marenzana M, Cavani F, Colasante F, Villa I, Willnecker J, Moro GL, Spreafico LP, Ferretti M, Guidobono F et al. (2008): Ovariectomy sensitizes rat cortical bone to whole-body vibration. Calcif Tissue Int $\underline{82}$ (4), 316-326

Ruyssen-Witrand A, Gossec L, Kolta S, Dougados M, Roux C (2007): Vertebral dimensions as risk factor of vertebral fracture in osteoporotic patients: a systematic literature review. Osteoporos Int 18 (9), 1271-1278

Sehmisch S, Erren M, Rack T, Tezval M, Seidlovka-Wuttke D, Richter J, Wuttke W, Stürmer KM, Stürmer EK (2009a): Short-term effects of parathyroid hormone on rat lumbar vertebrae. Spine $\underline{34}$ (19), 2014-21

Sehmisch S, Galal R, Kolios L, Tezval M, Dullin C, Zimmer S, Stürmer KM, Stürmer EK (2009b): Effects of low-magnitude, high-frequency mechanical stimulation in the rat osteopenia model. Osteoporose Int 20 (12), 1999-2008

Sioka C, Fotopoulos A, Georgiou A, Xourgia X, Papadopoulos A, Kalef-Ezra JA (2009): Age at menarche, age at menopause and duration of fertility as risk factors for osteoporosis. Climacteric $\underline{13}$ (1), 63-71

Siris E, Adachi JD, Lu Y, Fuerst T, Crans GG, Wong M, Harper KD, Genant HK (2002): Effects of raloxifene on fracture severity in postmenopausal women with osteoporosis results from the MORE study. Multiple Outcomes of Raloxifene Evaluation. Osteoporos Int $\underline{13}$, 907-913 
Slatkovska L, Alibhai SM, Beyene J, Cheung AM (2010): Effect of wholebody vibration on BMD: a systematic review and meta-analysis. Osteoporos Int 21 (12), 1969-80

Smith EL, Gilligan C, McAdam M, Ensign CP, Smith PE (1989): Deterring bone loss by exercise intervention in premenopausal and postmenopausal women. Calcif Tissue Int $\underline{44}$ (5), 312-21

Stürmer EK, Komrakova M, Werner C, Wiecke M, Kolios L, Sehmisch S, Tezval M, Utesch C, Mangal O, Zimmer S et al. (2010): Body vibration during fracture healing in intact and ovariectomized rats. Calcif Tissue Int $\underline{87}$ (2), 168-180

Stürmer EK, Seidlova-Wuttke D, Sehmisch S, Rack T, Wille J, Frosch KH, Wuttke W, Sturmer KM (2006): Standardized bending and breaking test for the normal and osteoporotic metaphyseal tibias of the rat: Effect of estradiol, testosterone, and raloxifene. J Bone Miner Res 21, 89-96

Stürmer KM (1980): Mikroradiographie des Knochens, Technik, Aussagekraft und Planimetrie. Hefte Unfallheilkunde 148, 247-251

Thompson DD, Simmons HA, Pirie CM, Ke HZ (1995): FDA Guidelines and animal models for osteoporosis. Bone 17 (4), 125-133

Torvinen S, Kannus $P$, Sievänen $H$, Järvinen TA, Pasanen $M$, Kontulainen S, Nenonen A, Järvinen TL, Paakkala T, Järvinen M, Vuori I (2003): Effect of 8-month vertical whole body vibration on bone, muscle performance, and body balance: a randomized controlled study. J Bone Miner Res 18 (5), 87684

Turner CH, Takano Y, Owan I (1995): Aging changes mechanical loading thresholds for bone formation in rats. J Bone Miner Res $\underline{10}$ (10), 1544-9

Turner CH, Warden SJ, Bellido T, Plotkin LI, Kumar N, Jasiuk I, Danzig J, Robling AG (2009): Mechanobiology of the skeleton. Sci Signal 2 (68), pt3

Utesch C: Einfluss der vertikalen Ganzkörpevibration auf die metaphysäre Frakturheilung der gesunden und osteoporotischen Tibia im RattenTiermodell. Med. Diss. Göttingen 2016

Verhas M, Schoutens A, L'Hermite-Baleriaux M, Dourov N, Verschaeren A, Mone M, Heilporn A (1986): The effect of orchidectomy on bone metabolism in agingrats. Calcif Tissue Int $\underline{39}$, 74-77 
Verschueren SM, Roelants M, Delecluse C, Swinnen S, Vanderschueren D Boonen S (2004): Effect of 6-month whole body vibration training on hip density, muscle strength, and postural control in postmenopausal women: a randomized controlled pilot study. J Bone Miner Res 19 (3), 352-359

Vezeridis PS, Semeins CM, Chen Q, Klein-Nulend J (2006): Osteocytes subjected to pulsating fluid flow regulate osteoblast proliferation and differentiation. Biochem Biophys Res Commun 348, 1082-1088

Warden SJ, Turner CH (2004): Mechanotransduction in the cortical bone is most efficient at loading frequencies of $5-10 \mathrm{~Hz}$. Bone $\underline{34,261-270}$

Watts NB (2004): Fundamentals and pitfalls of bone densitometry using dualenergy X-ray absorptiometry (DXA). Osteoporos Int $\underline{15}$ (11), 847-54

Wells G, Tugwell P, Shea B, Guyatt G, Peterson J, Zytaruk N, Robinson V, Henry D, O'Connel D, Cranney A et al. (2002): Meta-analysis of the efficacy of hormone replacement therapy in treating and preventing osteoporosis in postmenopausal women. Endocrin Res $\underline{23}, 529-539$

Wolff J: Das Gesetz der Transformation der Knochen. Berlin, Hirschwald 1892

Wronski TJ, Dann LM, Scott KS, Cintron LM (1989): Long-term effects of ovariectomy and aging on the rat skeleton. Calcif Tissue Int $\underline{45}, 360-366$

Wronski TJ, Yen CF, Scott KS (1991): Estrogen and diphosphonate treatment provide long-term protection against osteopenia in ovariectomized rats. J Bone Miner Res $\underline{6}$ (4), 387-94

Xie L, Jacobson JM, Choi ES, Busa B, Donahue LR, Miller LM, Rubin CT, Judex S(2006): Low-level mechanical vibrations can influence bone resorption and bone formation in the growing skeleton. Bone $\underline{39}$ (5), 10591066 


\section{Abbildungsverzeichnis}

Abbildung 1: Darstellung des Vibrationsgeräts ............................................ 26

Abbildung 2: Anatomie einer Ratte...................................................... 27

Abbildung 3: Fotografierter Sagittalschnitt des Corpus vertebrae ................. 29

Abbildung 4: Digitalisierter Sagittalschnitt des Corpus vertebrae.................. 30

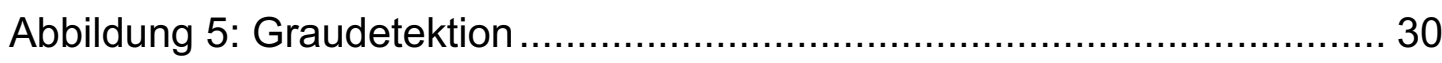

Abbildung 6: Gesamtfläche des Corpus vertebrae....................................... 31

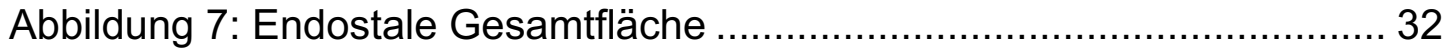

Abbildung 9: Bruchvorrichtung mit Lendenwirbelkörper ............................... 34

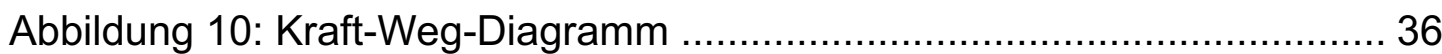

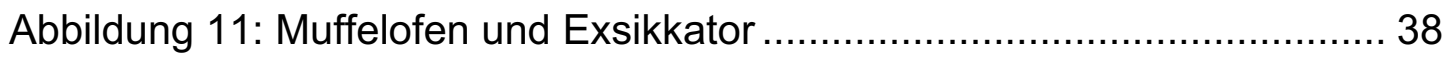

Abbildung 14: Kortikale Knochenflächendichte .......................................... 41

Abbildung 15: Dichte Trabekelkreuzungen ............................................ 42

Abbildung 16: Anzahl der Trabekelkreuzungen absolut ............................... 42

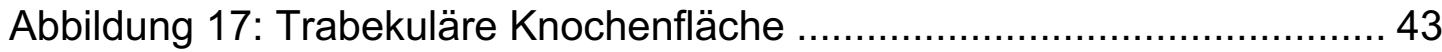

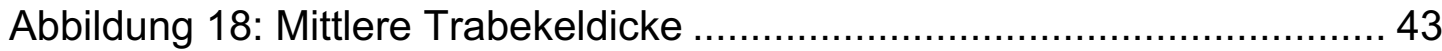

Abbildung 20: Maximalkraft in Bezug auf das Wirbelkörpervolumen ............ 45

Abbildung 21: Yield Load in Bezug auf das Wirbelkörpervolumen................ 45

Abbildung 22: Steigung in Bezug auf das Wirbelkörpervolumen .................. 46

Abbildung 23: Knochenmineraldichte in Bezug auf das Wirbelkörpervolumen 


\section{Tabellenverzeichnis}

Tabelle 1: WHO-Klassifikation der Osteoporose ..................................... 8

Tabelle 2: Ursachen einer sekundären Osteoporose ................................ 9

Tabelle 3: Risikofaktoren osteoporosebedingter Frakturen...................... 11

Tabelle 4: Indikation zur Medikamentösen Therapie in Abhängigkeit vom T-

Wert im Bezug zum Geschlecht und Alter......................................... 17

Tabelle 5: Aufteilung und Behandlung der Tiere ..................................... 24

Tabelle 6: Messparameter der Mikroradiographie.................................... 32

Tabelle 7: Ergebnisse der Messung der Tiergewichte und der

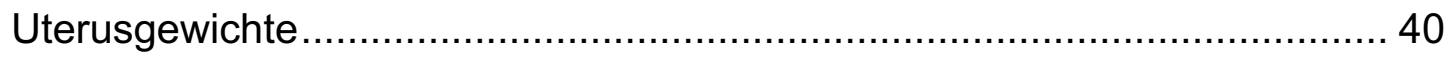

Tabelle 8: Ergebnisse der Serumanalyse ......................................... 40

Tabelle 9: Zusammenfassung der Ergebnisse der Mikroradiographie.......... 44

Tabelle 10: Zusammenfassung der Ergebnisse des biomechanischen

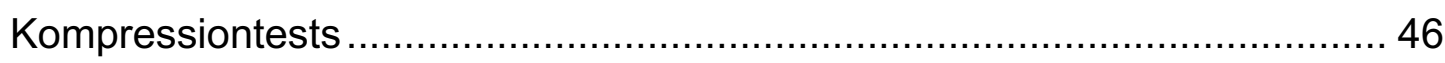

Tabelle 11: Ergebnisse der Knochenmineraldichte-Messung ................... 47 


\section{Danksagung}

Hiermit möchte ich meinen Dank an die Forschungsabteilung der Unfallchirurgie, Orthopädie und Plastischen Chirurgie und dem damaligen Klinikdirektor Herr Prof. Dr. med. Klaus-Michael Stürmer für die Ermöglichung des Projektes sowie dem nachfolgenden Klinikdirektor Herr Prof. Dr. med. Wolfgang Lehmann für die Aufrechterhaltung des Projektes aussprechen.

Mein besonderer Dank gilt Herrn Prof. Dr. med. Stephan Sehmisch, der mich als Doktorvater und Betreuer über das Projekt hinweg unterstütze. Seine offene, kompetente und zuverlässige Art in der Betreuung erleichterten mir die Umsetzung meiner Dissertation.

Ebenso möchte ich mich herzlich bei Frau Dr. rer. nat. Marina Komrakova für die fachlichen Auskünfte, Anregungen und motivierenden Gespräche bedanken.

Des Weiteren bedanke ich mich bei Frau Annette Witt, Ramona CastroMachguth und Herrn Friedrich Kauer für die anhaltende Unterstützung und Erreichbarkeit während des Versuchsablaufs und der folgenden Tätigkeiten im Labor.

Zudem möchte ich mich bei meiner Familie und Freunden für die moralische Unterstützung bedanken. Allen genannten Personen verdanke ich einen erfolgreichen Abschluss meiner Arbeit. 